Preoccupied and Dismissing Attachment Representations Are Differentially Associated with Anxiety in Adolescence and Adulthood: A Meta-Analysis*

*Paper accepted for publication in Clinical Psychological Science (ID \#CPX-19-0237.R1); 1/4/20

Or Dagan ${ }^{1}$, Christopher R. Facompré ${ }^{1}$, Marissa D. Nivison ${ }^{2}$, Glenn I. Roisman ${ }^{2}$, and Kristin Bernard ${ }^{1}$

${ }^{1}$ Department of Psychology, Stony Brook University, Stony Brook, NY ${ }^{2}$ Institute of Child Development, University of Minnesota, Minneapolis, MN

Correspondent author:

Or Dagan, Ph.D.

Department of Psychology, Stony Brook University

Stony Brook, NY, 11794

+1 - 646-270-1100 


\begin{abstract}
The claim that insecure attachment predisposes individuals to anxiety was put forth by attachment theorists more than 45 years ago, yet evidence of this association has produced mixed results. In a series of meta-analyses $(k=53, N=4970)$, we found that individuals with secure and insecure attachment representations did not differ in their reported anxiety symptoms. However, individuals with preoccupied $(d=0.35)$, but not dismissing attachment representations $(d=-0.02)$, endorsed significantly more anxiety symptoms than secure individuals. Individuals with preoccupied attachment representations also endorsed greater anxiety symptoms than those with dismissing attachment representations $(d=0.31)$, and this difference was stronger when assessed in high-risk samples than low-risk samples. Unresolved individuals were more anxious than non-unresolved individuals $(d=0.29)$, but exploratory analysis suggested that secondary preoccupied attachment subtype drove this effect. Results highlight the relevance of attachment representations for prevention and intervention efforts targeting anxiety.
\end{abstract}

Keywords: Attachment, anxiety, meta-analysis 


\section{Preoccupied and Dismissing Attachment Representations Are Differentially Associated with Anxiety in Adolescence and Adulthood: A Meta-Analysis}

Since the emergence of the discipline of clinical psychology at the end of the $19^{\text {th }}$ century, anxiety has been thought of as central to most, if not all, psychopathological disorders (Crocq, 2015, 2017). It is thus of little surprise that anxiety symptoms have not only been a core diagnostic feature of internalizing disorders (Eaton et al., 2013), and highly correlated with externalizing disorders (Bubier \& Drabick, 2009; Cosgrove et al., 2011), but also that anxiety disorders have been one of the most prevalent diagnosed mental illnesses across the lifespan; approximately 1 in 15 people are diagnosed with anxiety disorder every year globally (Steel et al., 2014) — the highest of all mental disorders. Depending on the anxiety disorder and the population assessed, lifetime prevalence of anxiety falls anywhere between $3.8 \%$ and $25 \%$ (Remes, Brayne, Van Der Linde, \& Lafortune, 2016). Importantly, some studies suggest that subthreshold anxiety disorders may be 3 times higher (Angst, Merikangas, \& Preisig, 1997; Balázs et al., 2013). Anxiety is one of the leading causes of poor health and mortality across all mental disorders (Simpson, Neria, Lewis-Fernandez, \& Schneier, 2010; Walker, McGee, \& Druss, 2015); second to depression, anxiety causes the most years lost due to ill-health, disability, or early death among mental disorders (Kessler, Petukhova, Sampson, Zaslavsky, \& Wittchen, 2012; Whiteford et al., 2013). It has thus become increasingly clear that the etiology and maintenance of anxiety are of great clinical importance.

Individuals who experience anxiety often have chronic thoughts characterized by overestimation of threats and harm (Bar-Haim, Lamy, Pergamin, Bakermans-Kranenburg, \& van IJzendoorn, 2007; Garnefski \& Kraaij, 2018). Importantly, interpersonal mechanisms play a role in the emergence of anxiety symptoms (Diamond \& Aspinwall, 2003; Nolte, Uiney, Fonagy, 
Mayes, \& Luyten, 2011), emphasizing the relational nature of anxiety symptoms. The interpersonal aspect of anxiety may be understood in one of two ways. First, anxiety may arise from interpersonal interactions that are perceived as threatening, contributing to anxiety disorders such as social anxiety (e.g., when one fears being criticized by others; Alden \& Taylor, 2010) and separation anxiety disorder (e.g., when one fears that the attachment figure may be harmed when separated from them; Bögels, Knappe, \& Clark, 2013). Additionally, anxiety may arise from the sense that support from others may be difficult to solicit, or unavailable altogether, when needed (Cassidy, 1995; Mikulincer \& Shaver, 2012; Thompson, 2001).

Attachment theory proposes a comprehensive approach to understanding the formation of representations of interpersonal experiences with one's caregivers under distress (Atkinson \& Goldberg, 2003; Bowlby, 1951; Mikulincer \& Shaver, 2012). Given that chronic distress may cause anxiety (McEwen et al., 2015; Patriquin \& Mathew, 2017), attachment theory offers a critical framework for better understanding the etiology of anxiety symptoms.

\section{From Early Distress About Unavailability of Caregivers to Anxiety Symptoms}

From an attachment theory perspective, anxiety across the lifespan is understood to be rooted in early anxiety regarding the availability of attachment figures (Bowlby, 1973; Sroufe, 1996). Put another way, when caregivers are unavailable or insensitive, children may experience worry or anxiety about their inability to solicit support at times of distress. In such rearing environments, children may adopt 'second-best' attachment strategies aimed to attenuate anxiety (Main, 1981, 1990). Some children may maximize their chances of soliciting support from the caregiver by both profusely protesting the caregiver's previous absence and attempting to prevent the caregiver from leaving again (also referred to as hyperactivating attachment strategies; Kobak, 1993). Other infants may minimize the distress that accompanies their 
perceived inability to solicit support from the caregiver by shifting attention away from the source of threat (also referred to as deactivating attachment strategies; Kobak, 1993).

Although hyperactivating and deactivating strategies may be adaptive in an environment where support is unlikely to be available, chronically relying on such strategies may, in interaction with other intra- and inter-personal factors, lead to appraising threats as overwhelming (Britton, Lissek, Grillon, Norcross, \& Pine, 2011; Mineka \& Zinbarg, 2006), and thus to anxiety symptoms later in life (Carlson \& Sroufe, 1995; Cassidy, 1995; Esbjørn, Bender, Reinholdt-Dunne, Munck, \& Ollendick, 2012; Kerns \& Brumariu, 2014). Specifically, it has been proposed that the inability of insecurely attached individuals to effectively regulate emotions at times of distress may lead to anxiety symptoms (Esbjørn et al., 2012; Kerns \& Brumariu, 2014; Nolte et al., 2011; Sroufe, Duggal, Weinfield, \& Carlson, 2000; Thompson, 2001).

Emotion regulation refers to the ability to "...influence which emotions we have, when we have them, and how we experience and express them" (Gross, 1998), and is thought to develop early in life via repeated infant/child-caregiver interactions at times of distress (Sroufe et al., 2000). Given that anxiety often entails difficulties managing emotional arousal and the intense experience of negative emotions (Gross, 2015), and that attachment behaviors are at their core geared towards regulating negative emotions (e.g., seeking comfort; Thompson, 2001), developing insecure attachment early in life may lead to chronic inability to mitigate distress and arousal. Prolonged distress and arousal, in turn, may expose insecurely attached individual to anxiety symptoms. Indeed, some studies suggest that insecure infants have been shown to more frequently develop anxiety later in childhood and adolescence compared to their secure peers (Bar-Haim, Dan, Eshel, \& Sagi-Schwartz, 2007; Bosquet \& Egeland, 2006; Brumariu \& Kerns, 
2013; Colonnesi et al., 2011; Manassis, 2001; Stuart Parrigon \& Kerns, 2016; Warren, Huston, Egeland, \& Sroufe, 1997), though meta-analytic evidence suggests this association is weak in magnitude (e.g., $d=.15$; Groh et al., 2012).

\section{Attachment Representations}

Repeated early experiences that infants have with caregivers at times of need give rise to mental representations of attachment (Bowlby, 1973; Bretherton \& Munholland, 2008). These attachment representations have been thought to entail a model of emotions and expectations with respect to oneself and others that shapes adult interpersonal behavior at times of distress (Bretherton, 1985, 1991, 1992; Sroufe, Egeland, Carlson, \& Collins, 2005; Sroufe \& Waters, 1977). The most widely used objective assessment of attachment representations in adolescence and adulthood is the Adult Attachment Interview (AAI; George, Kaplan, \& Main, 1985).

The AAI is a semi-structured interview about one's early experiences with primary caregivers that includes questions that pertain to both the quality of such experiences as well as their influence on who the speaker is at present. The AAI measures attachment patterns by assessing the quality or "coherence" of the speaker's discourse (Hesse, 2016). In this context, attentional (in)flexibility- a hallmark of anxiety or lack thereof (Mogg \& Bradley, 2016; Pacheco-Unguetti, Acosta, Callejas, \& Lupiáñez, 2010)- can be observed in adults' discourse during the AAI. Securely attached individuals are able to fluidly shift their focus between their memories of attachment-related experiences and respond to AAI questions in a collaborative manner (e.g., consistent or truthful), such as to evaluate the influences of these past experiences on the speaker's present personality (Hesse, 2016). This capacity for attentional flexibility is thought to reflect a relative absence of attentional biases that is often observed in anxious individuals (Cisler \& Koster, 2010; Ferreri, Lapp, \& Peretti, 2011). However, individuals 
classified as insecurely attached on the AAI tend to exhibit attentional inflexibility. For example, such individuals tend to exhibit discourse that is irrelevant to the topic at hand (e.g., not directly answering the question) or not matching the expected quality of information provided (e.g., excessively succinct or angrily elaborative). Accordingly, instead of collaborating with the interviewer on the present interview task, insecurely attached individuals are thought to rigidly direct their cognitive effort to regulating their emotions in face of attachment-related anxiety, associated with memories about past and present distressful experiences with their primary caregivers (Main, 2000).

Insecure-dismissing (hereafter, 'dismissing') individuals tend to use 'deactivating' strategies when presented with the AAI questions; they turn away from past negative experiences by either idealizing their caregivers without substantiating their idealization with concrete examples (and sometimes insist on lack of recall), or exhibiting brief derogation of their caregivers (Hesse, 2016) followed by reluctance to elaborate further. In contrast, insecurepreoccupied (hereafter, 'preoccupied') individuals tend to use 'hyperactivating' strategies when asked about the past experiences with their parents. Exhibiting high frequency and/or intense anger, confusion, or fearfulness during the AAI are common in preoccupied individuals, who are over-involved with negative past and present experiences (Hesse, 2016).

Finally, a disorganized classification-referred to as unresolved—-may be assigned based on an individual's responses during AAI. Unresolved attachment in adulthood manifests as disorientation when under the distress; for unresolved adults, disorientation is exhibited as lapses in monitoring of reasoning or discourse during discussion of past loss or abuse (Hesse \& Main, 2006). Of note, an unresolved classification is assigned in addition to one of the primary organized classifications, though it should be noted that large sample factor analyses of the AAI 
reliably report that indicators of unresolved attachment and indicators of preoccupied attachment load on a common construct (e.g., Haltigan, Roisman, \& Haydon, 2014; Roisman \& Cicchetti, 2017).

\section{Attachment Representations and Anxiety: A Brief Review of Findings}

Despite the rich theoretical underpinning and nearly four decades of research on adult attachment and psychopathology, only a few studies have reported on the link between attachment representations and anxiety symptoms. Brumariu and colleagues (2013) explored the association between attachment representations and anxiety among older adolescents with anxiety disorders. The authors reported that insecure and unresolved attachment patterns were more represented in a group of individuals with anxiety disorders than a group with no psychopathological diagnoses. Another study assessed adults diagnosed with anxiety disorders to examine a potential mechanisms by which insecurely attached individuals selectively process threatening information (Van Emmichoven, Van IJzendoorn, De Ruiter, \& Brosschot, 2003). Results suggested that securely attached patients with anxiety disorders showed larger emotional Stroop interference for threatening words and better recall for threatening words than their insecure counterparts. The authors suggested that securely attached patients were more focused on, and open to processing, threatening words and less defensive than insecurely attached patients. Accordingly, the authors concluded that insecure attachment in general, but not the subtype of insecurity (i.e., preoccupied and dismissing), is associated with anxiety-related attention and memory defensive processes.

Other studies reported that individuals classified with preoccupied (but not dismissing) and unresolved attachment representations were overrepresented in adults with anxiety disorders (e.g., Fonagy et al., 1996; Manassis, Bradley, Goldberg, Hood, \& Swinson, 1994; Rosenstein \& 
Horowitz, 1996; Stovall-McClough \& Cloitre, 2006). A few studies that assessed the link between AAI classifications and anxiety symptoms in non-clinical populations (e.g., Adam, Gunnar, \& Tanaka, 2004; Kobak \& Sceery, 1988; Pianta, Egeland, \& Adam, 1996) reported similar results.

Of note, one meta-analysis reported the distribution of AAI classifications in samples of individuals diagnosed with internalizing disorders (Bakermans-Kranenburg \& Van IJzendoorn, 2009), which tend to include anxiety symptoms (e.g., Krueger \& Markon, 2006). In studies comparing non-clinical and internalizing disorder samples, preoccupied attachment was overrepresented in all participants with internalizing disorders, and unresolved attachment was overrepresented in individuals diagnosed with borderline personality disorder or with a history of severe suicidal ideation. However, this meta-analytic study was limited in its ability to test specific associations between attachment representations and anxiety symptoms, given that it only included one study with an anxiety-disordered sample. Moreover, associations between attachment representations and anxiety symptoms in non-clinical populations were not examined.

Taken together, research suggests that adolescents and adults classified with unresolved and insecure attachment representations are more prone to anxiety symptoms and anxiety disorders than securely attached individuals. However, significant gaps in this literature remain. First, as noted by Fortuna and Roisman (2008), most of the studies that reported on the link between attachment representations and psychopathology, including anxiety, did so by studying clinical samples. Given that many individuals experience significant levels of distress that fall short of categorical diagnosis but require mental health care (Helmchen \& Linden, 2000; Kotov et al., 2017), examining the link between adult attachment patterns and anxiety symptoms within 
non-clinical samples is critical. By leveraging unpublished data from the large number of studies that measured attachment along with broad based measures of psychopathology (e.g., Symptom Checklist 90; Derogatis \& Cleary, 1977) in non-clinical samples, the association between attachment classifications and anxiety symptoms in such samples can be estimated alongside the published results regarding clinical samples. Second, increasing evidence has identified psychopathology as dimensional rather than categorical (e.g., Haslam, Holland, \& Kuppens, 2012; Widiger \& Samuel, 2005; Wright et al., 2013). As such, there is a need to summarize and quantify findings regarding the link between attachment representations and dimensionally assessed anxiety symptoms. Third, it is still unclear whether risk for developing anxiety symptoms differs between individuals classified as dismissing versus preoccupied attachment subtypes (Groh, Roisman, van IJzendoorn, Bakermans-Kranenburg, \& Fearon, 2012). As argued before (Kerns \& Brumariu, 2014; Stovall-McClough \& Dozier, 2016), understanding whether the different insecure subtypes carry differential risk for developing anxiety may inform attachment based prevention and intervention efforts.

\section{The Current Study}

In this meta-analysis, we aimed to quantify the magnitude of the association between attachment representations and anxiety symptoms in both clinical and non-clinical samples. Following previous meta-analyses (Colonessi et al., 2011; Dagan, Facompré, \& Bernard, 2018; Madigan, Atkinson, Laurin, \& Benoit, 2013), we compared anxiety symptoms between the following attachment groups: (a) insecure and secure individuals; (b) dismissing and secure individuals; (c) preoccupied and secure individuals; (d) preoccupied and dismissing individuals; and (e) unresolved and organized individuals. We also compared anxiety symptoms between (f) 
unresolved/dismissing and unresolved/preoccupied individuals to assess whether differences between insecure attachment patterns emerged above and beyond unresolved status.

We hypothesized that individuals with insecure attachment representation would show significantly more anxiety symptoms than securely attached individuals. Given that dismissing and preoccupied attachment representations are thought to reflect ineffective and inflexible strategies for regulating distress (Main, 2000; Shaver \& Mikulincer, 2007), we hypothesized that insecure individuals would show higher rates of anxiety than secure individuals. We also predicted that preoccupied individuals would report more anxiety than dismissing individuals given that this pattern emerged in related meta-analytic work with depression (Dagan et al., 2018). Lastly, we hypothesized that individuals with unresolved attachment patterns would exhibit more anxiety symptoms than individuals with resolved attachment patterns.

We examined several sample characteristics as potential moderators. Given established associations with anxiety symptoms, we examined whether the association between attachment and anxiety symptoms was moderated by demographic variables, including age, gender, parental status, ethnicity, socioeconomic status (SES), education, and author-identified risk status (Carter, Mitchell, \& Sbrocco, 2012; McLean, Asnaani, Litz, \& Hofmann, 2011; Orcutt, Garcia, \& Pickett, 2016). Moreover, we considered two methodological factors as potential moderators. The first was the AAI coding system from which attachment representations were drawn. That is, we compered the traditional Main classification coding system (George et al., 1985) to Kobak’s Q-set coding system (Kobak, 1993; Kobak, Cole, Ferenz-Gillies, Fleming, \& Gamble, 1993). The second potential methodological moderator we considered was the time interval between AAI and anxiety symptoms assessment, given that anxiety symptoms may change over time. 


\section{Method}

\section{Literature Search}

Peer-reviewed articles and dissertations examining the association between attachment representations and anxiety disorders and symptoms were retrieved for inclusion in this metaanalysis. The electronic databases PsycINFO, PubMed, and ProQuest were first searched in November of 2018 (and again in March of 2019) using some combination of the following keywords: attach* or “attachment behavior" or "adult attachment interview" or "AAI" or representation* or "mentalization" or "preoccupied” or "dismissing” AND anx* or psychopath* or "mental disorder" or "stress" or "symptom" or "distress" or "Achenbach Child Behavior Checklist" or "Symptom Checklist-90" or "Mental Health Inventory" or "Structured Clinical Interviews" or "Beck Anxiety Inventory" or "Brief Symptom Inventory" or "State-Trait Anxiety Inventory" or "State Trait Anxiety Inventory” or "Hospital Anxiety and Depression Scale”. Clinical case studies, pilot studies, and systematic reviews were excluded. No date or geographical restrictions were applied; however, studies were limited to those published in the English language. We also reviewed the reference sections of relevant research articles and book chapters to identify studies that may not have been retrieved through our electronic search.

References of 3,071 studies were imported into the online systematic review manager, Covidence, for screening, and 17 additional studies were identified through other sources. After removing duplicate reports, 1,244 studies were evaluated for study relevance based on the title and abstract. When study relevance could not be gleaned, the full-text article was screened. Four hundred and sixty-four full-text articles were reviewed, with 426 failing to meet the inclusion criteria. In some cases, multiple articles presented data on the same set (or subset) of participants. When duplicate samples were identified, we selected and cited the study with the largest sample and excluded the others to avoid redundancy. If more than one article reported 
the same sample size, we cited the more recent paper. This resulted in a final set of 36 studies (53 samples) that met inclusion criteria for at least one meta-analytic comparison (see Figure 1).

Of note, several studies recruited and combined multiple independent subgroups to maximize statistical power. For the purpose of meta-analysis, potentially meaningful sample differences can become obscured when combined. We therefore requested that (when possible) authors send the raw data for each sample so that effect size estimates could be computed and entered into the meta-analysis separately.

We also identified several studies that reported codable effects from one or more dependent samples (e.g., anxiety and attachment measures were administered to romantic couples). Dependent samples can produce biased sample estimates when simultaneously supplied to meta-analysis given that meta-analytic methods assume independence. Some recommend that meta-analysts simply choose one sample for inclusion (Lipsey \& Wilson, 2001). However, in the interest of maximizing statistical power, we elected to include all available dependent samples, but to test for their relative influence on the meta-analytic results post-hoc. This was done by randomly deleting one dependent sample at a time and examining changes to the mean effect. Across meta-analytic comparisons, effect sizes were computed for 53 samples (for a description of samples, see Table 1).

\section{Criteria for Study Inclusion}

Studies were considered eligible if they measured attachment representation via the AAI in association with anxiety symptoms. Because strict adherence to the AAI protocol is critical for interviews to be scored properly and reliably, studies using a modified version of the AAI were excluded. We did, however, identify a handful of cases in which the final question of the AAI ("What would you hope your child might have learned from his/her experiences of being parented by you?") was modified for use with adolescent participants. We decided to include 
these data given that this slight adaption is unlikely to significantly impact one's attachment classification. Studies were additionally limited to those that assessed trait-anxiety (as opposed to state-anxiety). Trait-anxiety is thought to reflect stable individual differences that increase one's propensity to respond psychologically and/or physiologically to threatening situations, thus making it a more suitable outcome of interest.

In line with other meta-analyses on anxiety-related disorders (e.g., Bandelow et al., 2015; Otowa et al., 2016), we excluded studies $(k=4)$ that compared participants with clinically diagnosed mental health comorbidity to participants without any mental health disorders. This decision was made to exclude known confounders that may influence the link between attachment representations and anxiety symptoms (e.g., major depressive disorder in participants with anxiety-related disorders). Of note, the vast majority of the studies assessed in this metaanalysis did not assess for mental health comorbid conditions; thus, it is likely that participants included in this meta-analysis had varying degrees of comorbid symptoms.

In terms of effect size data, studies were included if they reported: (a) mean differences in anxiety symptoms between attachment classification groups, (b) frequency counts of clinically anxious versus non-anxious individuals across attachment classifications, or (c) the correlation between attachment classification (continuously measured via the AAI Q-Sort) and anxiety symptoms. For studies investigating an intervention of any kind, only pre-intervention baseline assessments and/or control group data were coded. When studies reported effects on the same sample at multiple time points, the time point with the largest sample size was selected.

We faced two notable challenges when coding effect sizes from research reports. First, in many cases, authors reported on global symptom sum scores instead of anxiety sub-scale scores (e.g., the SCL-90-R was administered, but no anxiety subscale scores were reported). Second, 
for individuals with unresolved attachment, secondary classifications (e.g., unresolved/preoccupied versus preoccupied; unresolved/dismissing versus dismissing) were rarely reported. As a result, authors were asked to provide raw data so that effect sizes for all possible comparisons could be computed. In total, 61 authors were contacted. Of these, 37 could not be reached via the email provided or returned data in a non-useable form.

\section{Coding of Moderator Variables}

Several study/sample descriptors and methodological variables were coded as potential moderators. Study descriptors included: (a) publication year, (b) country in which data were collected, and (c) whether the research report was a peer-reviewed article or dissertation. Sample descriptors included: (d) participants' mean age in years, (e) mean age dichotomized as "adult" (age 18 years or above) or "adolescent" (age less than 18 years), (f) biological sex, coded as percent female; $(\mathrm{g})$ the percentage of the sample that were parents, (h) parent status dichotomously coded as "parent" (percent parent greater than or equal to 60\%) or "non-parent" (percent parent less than 60\%), (i) the percentage of the sample that was White, and (j) race dichotomously coded as "majority White" (greater than 60\%) or "majority non-White" (less than or equal to $60 \%)$.

We also coded several risk factors thought to contribute to anxiety symptoms and/or attachment classification. These included: (a) SES, dichotomized as primarily low or primarily middle/high, (b) mean years of education, (c) mean level of education dichotomized as "some college or more" (greater than $50 \%$ of the sample) or "high school or less", and (d) overall risk status based on whether authors made explicit mention of risk factors.

Finally, we coded several methodological variables. These included: (a) the type of AAI coding used (Main classification system or Attachment Q-Sort), and (b) the amount of time between AAI and anxiety assessments coded as "concurrent" (less than or equal to one month 
apart) or "non-concurrent" (greater than 1 month apart). Notably, when data could be computed from multiple methods of attachment and anxiety, preference was given to the Main classification system and self-report measures, respectively.

Given the number of comparisons tested, the relatively low proportion of individuals classified as insecure subtypes, and the strong reliance on author-provided data, in most cases, moderator variables were coded on the basis of study-level descriptors. Thus, for some comparisons, coded moderator values are a close approximation and not exact descriptions of individuals included in a given meta-analysis (e.g., mean age for the full sample entered for comparisons with less datapoints such as preoccupied versus dismissing).

Coding was performed by the first and second authors. After establishing reliability on a small subset of studies, both authors coded all studies independently. Studies used to establish initial reliability were returned to the end of the coding list to avoid remembering details of the study and/or consensus ratings. Interrater reliability for continuous moderator variables and those used to compute the effect size statistic was conducted using the ICC (average measures, absolute agreement). Categorical moderator variable reliability was conducted using Cohen's kappa. When a single study provided more than one effect size, redundant study and research design descriptors undergoing moderation testing were first deleted to reduce the likelihood of inflating the reliability statistic (e.g., year of publication). Reliability among continuously coded moderator and effect size variables were high (mean $\mathrm{ICC}=.97$, range $=.93$ to 1.0 and mean $\mathrm{ICC}$ $=.99$, range $=.82$ to 1.0 , respectively). Reliability among categorically coded moderators was also high $($ mean kappa $=.87$, range $=.74$ to 1.0$)$. All disagreements were resolved through consensus.

\section{Data Analysis Strategy and Coding of Effect Sizes}


Effect sizes were calculated using the 'metafor' package for the statistical software R (R Core Team, 2019; Viechtbauer, 2010). Raw means and standard deviations of anxiety by attachment classification were computed as a standardized mean difference (Cohen's $d$ ). As is common in meta-analysis, studies also reported data in several other statistical forms. One study, for example, reported 2 by 2 frequency counts of anxious and non-anxious participants by their assigned attachment classification. Others applied a dimensional rating of attachment security and anxiety (e.g., AAI Q-Sort). In all cases, data were coded in their raw form (frequency counts, correlation coefficients) and transformed into the standardized mean difference prior to analysis so that they could be combined with studies reporting on the mean difference.

Data for meta-analysis were fit to a random-effects model using the restricted maximumlikelihood estimator (Borenstein, Hedges, Higgins, \& Rothstein, 2011; Viechtbauer, 2005, 2010). Data were organized such that positive effect sizes represent increased anxiety symptoms with attachment insecurity. Because some meta-analytic comparisons either compared two types of insecure attachment directly (e.g., preoccupied versus dismissing) or compared participants with unresolved versus non-unresolved attachment status (e.g., resolved versus unresolved, unresolved/dismissing versus dismissing, unresolved/preoccupied versus preoccupied), additional considerations were made with respect to effect size direction. When applicable, positive effect sizes were set to indicate higher rates of anxiety among individuals with: (a) unresolved status than individuals with resolved status, (b) preoccupied attachment than individuals with dismissing attachment, and (c) unresolved/preoccupied attachment than individuals with unresolved/dismissing attachment. 
Heterogeneity in the mean effect observed among moderator variables were explored using the Q-statistic. Following evaluation of heterogeneity, continuous and categorical moderators were conducted under a mixed effects model with meta-regression (when applicable). Of note, moderator data was missing to various degrees - a ubiquitous challenge in meta-analysis. Analysis of moderator variables with less than four data points at a given level were not conducted to avoid unstable moderation effects, consistent with previous work (e.g., Bakermans-Kranenburg, Van IJzendoorn, \& Juffer, 2003). Following procedures described in Viechtbauer and Cheung (2010), influential and outlying case diagnostics were conducted and evaluated one at a time to estimate their relative impact on the meta-analytic results.

\section{Publication Bias}

Publication bias for each meta-analytic comparison was evaluated using Duval and Tweedie's (2000b, 2000a) trim and fill procedure. The trim and fill procedure estimates funnel plot asymmetry, filling potentially "missing" datapoints on either side of the effect size distribution. The $\mathrm{x}$-axis of the graph represents the effect size magnitude, whereas the $\mathrm{y}$-axis reflects the precision of the effect. Studies missing toward the bottom left side of the funnel plot are thought to indicate publication bias (file drawer), given that small nonsignificant effects tend not to be published. In addition, to the graphical output, the trim and fill procedure provides a statistical adjusted mean effect size that can be compared to the mean effect from the observed data. Importantly, meta-analytic comparisons with less than 10 samples did not undergo publication bias analyses.

\section{Results}

\section{Secure versus Insecure Attachment}

The primary outcome in this meta-analysis was the standardized mean-difference $(d)$ in anxiety symptoms between individuals with secure and insecure attachment representations. 
Participants comprising the secure group included those classified as secure regardless of whether they carried a primary unresolved classification. In total, 50 samples and 4,682 participants contributed to this meta-analysis, with effect sizes ranging from -1.30 to 1.24 (Figure SOM-U1). The overall random effects estimate was $d=0.07$ (95\% CI $=-0.02$ to 0.15$)$. Results suggested that, on average, individuals classified as secure and insecure do not differ in their anxiety symptoms. In addition to the confidence interval, which provides an estimate of statistical precision around the mean effect, Higgins' 95\% prediction interval (PI) estimates the range of true effects that might be expected among similar studies in the future. The PI holds important clinical utility given that it provides a nuanced understanding of the variability of effects across different settings and should be routinely reported (for further discussion, see IntHout, Ioannidis, Rovers, \& Goeman, 2016). In the current meta-analysis, Higgins' 95\% PI ranged from -0.26 to 0.39 , suggesting that the effects for some populations under certain conditions could fall on either side of zero. The removal of potential outliers and/or influential cases did not significantly impact the meta-analytic result.

The proportion of variance observed among effect sizes was moderate $\left(I^{2}=29.17 \%, \tau^{2}=\right.$ .02 ), indicating heterogeneity among true effects, $Q(49)=80.72, p=.003$. Thus, study- and sample-level moderators were explored (see Table 2). Prior to analysis, continuous moderators were first centered around the mean to allow for interpretation of the intercept. Among the variables tested, only publication year significantly accounted for heterogeneity among true effects. On average, effect sizes became significantly smaller over time $\left(\beta_{1}=-0.02, p=.01\right)$. The test for residual heterogeneity was significant, however, suggesting that moderators not included in the model might account for additional unexplained variance in the mean effect $\left(Q_{E}=72.61\right.$, $d f=48, p=0.01)$. 


\section{Secure versus Dismissing Attachment}

We tested the standardized mean-difference $(d)$ in anxiety symptoms between individuals classified as secure and dismissing. Participants comprising the secure group included those described above. The dismissing group included individuals classified as dismissing regardless of whether they carried a primary unresolved classification. Overall, effect sizes from 50 samples and 4,376 participants were extracted, ranging from -1.32 to 0.94 (Figure 2a). The overall random effects estimate was $d=-0.02(95 \% \mathrm{CI}=-0.10$ to $0.05 ; 95 \% \mathrm{PI}=-0.27$ to 0.22$)$. Results suggested that individuals classified as securely attached did not differ in anxiety symptoms from those classified as dismissing. Several studies were identified as potential outliers and/or influential cases, and the removal of these studies did not significantly impact the meta-analytic result.

The proportion of variability observed among effect sizes was low $\left(I^{2}=19.69 \%, \tau^{2}=.01\right)$ but heterogeneity was detected among true effects $(Q=68.09, d f=49, p=0.04)$. Thus, studyand sample-level moderators were explored (see Table 2).

We found that SES and race significantly explained heterogeneity among true effects. First, low- and mid/high SES samples produced mean effects of $d=-0.23(p=.01)$ and $d=0.00$ $(p=.98)$, respectively. When directly compared, the omnibus test of the SES factor yielded a significant result $\left(Q_{M}=5.89, d f=1, p=.02\right)$, and the test for residual heterogeneity was nonsignificant $\left(Q_{E}=73.44, d f=36, p<.001\right)$. In addition, a small but significant increase in the effect size was found for every one-unit increase in race, coded as percent white $\left(\beta_{1}=0.003, p=\right.$ .03). Moreover, a significant difference in race was observed when coded categorically. The average effect sizes for sample featuring majority non-White samples was $d=-0.14(p=.04)$, whereas the mean effect for samples featuring majority White samples was $d=0.2(p=.57)$. 
When directly compared, the omnibus test of the dichotomous race factor yielded a significant result, $Q_{M}=4.24, d f=1, p=.04$. Finally, in both continuously and categorically coded race analyses, the test for residual heterogeneity was non-significant $\left(Q_{E}=27.07, d f=37, p=.88\right.$ and $Q_{E}=55.23, d f=45, p=.14$, respectively).

\section{Secure versus Preoccupied Attachment}

Next, we tested the standardized mean-difference $(d)$ in anxiety symptoms between individuals with secure and preoccupied attachment representations. The preoccupied group included participants with and without a primary unresolved classification. Altogether, this meta-analysis included 42 samples and 3,271 participants, with effect sizes ranging from -0.64 to 2.21 (Figure 2b). The overall random effects estimate was $d=0.35$ (95\% CI $=0.19$ to $0.50 ; 95 \%$ $\mathrm{PI}=-0.44$ to 1.14 ), suggesting that individuals classified as preoccupied reported higher anxiety symptoms than those classified as secure. The removal of these studies identified as potential outliers did not significantly impact the meta-analytic result.

The proportion of variability observed among effect sizes was moderate to high $\left(\mathrm{I}^{2}=\right.$ $\left.61.10 \%, \tau^{2}=.15\right)$, indicating heterogeneity among true effects, $Q(41)=99.53, p<.0001$. However, we found no significant moderator effects (see Table 2).

\section{Preoccupied versus Dismissing Attachment}

We also investigated the standardized mean-difference $(d)$ in anxiety symptoms between individuals with preoccupied and dismissing attachment representations. Preoccupied and dismissing groups were created following the same procedures described above. In total, 41 samples and 2,184 participants contributed to this meta-analysis, with effect sizes ranging from 0.89 to 2.01 (Figure SOM-U2). The overall random effects estimate was $d=0.31(95 \% \mathrm{CI}=$ 0.15 to $0.47 ; 95 \% \mathrm{PI}=-0.47$ to 1.08$)$, suggesting that individuals classified as preoccupied 
reported higher anxiety symptoms than those classified as dismissing. Although some studies were identified as potential outliers and/or influential cases, removing them did not significantly affect the magnitude of the obtained effect size.

The proportion of variability observed among effect sizes was moderate $\left(I^{2}=56.55 \%, \tau^{2}\right.$ $=.14)$, indicating heterogeneity among true effects, $Q(40)=88.99, p<.0001$, which was explained by several moderators (see Table 2). First, the average effect for samples featuring majority non-White participants and majority White participants was significant $(d=0.63, p<$ .001 and $d=0.23, p=.01$, respectively). Groups significantly differed from one another, such that the mean effect for majority white samples was $d=.41$ lower than majority white samples $\left(Q_{M}=4.32, d f=1, p=.04\right)$. Notably, the test for residual heterogeneity was significant $\left(Q_{E}=\right.$ 74.61, $d f=36, p<.001)$, suggesting that moderators not included in the model could account for additional unexplained variance in the mean effect.

Second, we found that the average effect for non-risk and high-risk samples was also significant $(d=0.22, p=.01$ and $d=0.73, p<.0001$, respectively). When directly compared, the omnibus test of the risk factor was significant $\left(Q_{M}=7.41, d f=1, p=.01\right)$, with high-risk samples showing a larger effect size than non-risk samples. Of note, moderators not included in the model might have accounted for additional unexplained variance in the mean effect ( $Q_{E}=$ 71.62, $d f=39, p=.001)$.

Third, average effect sizes for low-SES and mid/high-SES samples were significant $(d=$ $0.76, p<.001$ and $d=0.25, p=.004$, respectively). When directly compared, the omnibus test of the SES factor yielded a significant result $\left(Q_{M}=5.07, d f=1, p=.02\right)$, such that low-SES samples had significantly larger effect sizes than mid/high-SES samples. Notably, the test for residual heterogeneity was also significant $\left(Q_{E}=73.44, d f=36, p<.001\right)$. 
Finally, whereas studies for which the AAI and anxiety measures were administered concurrently showed a significant effect size $(d=0.62, p<.0001)$, the mean effect size of samples for which core assessments were administered non-concurrently (> 1 month apart) was not significantly different from zero $(d=0.04, p=.84)$. When directly compared, the omnibus test of the assessment factor yielded a significant result $\left(Q_{M}=4.81, d f=1, p=.03\right)$. The test for residual heterogeneity was also significant $\left(Q_{E}=38.00, d f=19, p=.01\right)$.

\section{Organized Versus Unresolved Attachment}

The primary outcome in this meta-analysis was the standardized mean-difference $(d)$ in anxiety symptoms between organized (i.e., resolved) and unresolved individuals. Participants comprising the unresolved group included all individuals carrying a primary unresolved classification regardless of their secondary (secure/insecure) classification. Thus, individuals classified as unresolved/secure were included in the unresolved group. In total, 28 samples and 3,316 participants contributed to this meta-analysis, with effect sizes ranging from -0.33 to 2.60 (Figure SOM-U3). The overall random effects estimate was $d=0.29$ (95\% $\mathrm{CI}=0.16$ to 0.42 ; $95 \% \mathrm{PI}=-0.11$ to 0.69$)$. Results suggested that, on average, individuals classified as unresolved reported higher anxiety symptoms than non-unresolved (i.e., organized) individuals. The removal of potential outliers and/or influential cases did not significantly impact the metaanalytic result.

The proportion of variability observed among effect sizes was moderate $\left(I^{2}=31.38 \%, T^{2}\right.$ $=.03$ ), indicating heterogeneity among true effects, $Q(27)=46.29, p=.01$. No significant moderator effects were found (see Table 2).

Further Exploratory Meta-Analyses 
To explore the extent to which insecure attachment subtypes drive differences in anxiety symptoms among unresolved attachment classifications, we conducted a series of post-hoc comparisons. These included: (a) unresolved/dismissing versus dismissing, (b) unresolved/preoccupied versus preoccupied, and (c) unresolved/preoccupied versus unresolved/dismissing. Given the relatively low number of samples included in these narrower meta-analytic comparisons, these results should be interpreted with caution. Due to limited variability in coded moderator variables, we took a conservative approach and did not explore moderation.

Unresolved/dismissing versus dismissing. The standardized mean-difference $(d)$ in anxiety symptoms among dismissing participants with and without a primary unresolved classification was obtained. Five samples and 554 participants contributed to this meta-analysis, with effect sizes ranging from -0.32 to 0.25 . The overall random effects estimate was $d=0.06$ $(95 \% \mathrm{CI}=-0.21$ to $0.33 ; 95 \% \mathrm{PI}=-0.38$ to 0.50$)$. The results suggested that individuals who were classified as unresolved/dismissing reported similar levels of anxiety as dismissing individuals. The proportion of heterogeneity among effect sizes was non-significant, $Q=1.99$, $d f=4, p=.74$.

Unresolved/preoccupied versus preoccupied. Anxiety symptoms among preoccupied participants with and without a primary unresolved classification were also compared. In total, five samples and 140 participants contributed to this meta-analysis, with effect sizes ranging from -0.12 to 0.52 . The overall random effects estimate was $d=0.13$ (95\% $\mathrm{CI}=-0.24$ to 0.49 ; $95 \% \mathrm{PI}=-0.46$ to 0.72 ). Results suggested that individuals classified as unresolved/preoccupied and those classified as preoccupied did not significantly differ in their anxiety symptoms. The test of heterogeneity was also non-significant, $Q=1.31, d f=4, p=.86$. 
Unresolved/preoccupied versus unresolved/dismissing. In this meta-analysis, the standardized mean-difference in anxiety symptoms among unresolved/preoccupied and unresolved/dismissing participants was computed from 6 samples and 142 participants. Effect sizes ranged from 0.32 to 0.73 , producing an overall mean effect of $d=0.55$ (95\% $\mathrm{CI}=0.20$ to $0.89 ; 95 \% \mathrm{PI}=0.06$ to 1.03$)$. Results suggested that unresolved/preoccupied individuals reported significantly higher anxiety symptoms than those classified as unresolved/dismissing. The test of heterogeneity was also non-significant, $Q=0.69, d f=5, p=.98$.

\section{Publication Bias}

Among the five primary meta-analytic comparisons tested for publication bias, the trim and fill procedure identified funnel plot asymmetry for two of them. Two potentially missing studies on the right side (positive effect sizes) were identified for the secure versus dismissing comparison, while five potentially missing studies on the left side (negative effect sizes) were identified for the organized versus unresolved comparison (see Figure 3). The adjusted mean effect size for both comparisons was $d=-0.01, p=.73$ (observed sample $d=-0.02, p=.53$ ) and $d=0.21, p=.009$ (observed sample $d=0.29, \mathrm{p}<.0001$ ), respectively. We thus concluded that publication bias did not appear to significantly impact the meta-analytic results.

\section{Discussion}

This meta-analysis aimed to quantify the association between adult attachment representations coded from the AAI and anxiety symptoms. Interestingly, individuals classified as insecure in their attachment representation were no more likely to experience anxiety symptoms than secure individuals. When insecure sub-classifications were tested independently, however, preoccupied, but not dismissing individuals, reported significantly more anxiety than secure individuals. Preoccupied individuals were also significantly more anxiety prone than 
individuals who were classified as dismissing. We also found that unresolved individuals were more likely to report anxiety than those with an organized attachment classification. Finally, exploratory analyses revealed that unresolved/preoccupied individuals exhibited significantly more anxiety symptoms than unresolved individuals with a secondary classification of dismissing.

Interestingly, this pattern of results is largely consistent with recent meta-analytic work on the association between attachment representations and depression (Dagan, Facompré, et al., 2018). With the exception of the overall secure-insecure meta-analysis (which produced a significant positive effect of $d=.21$, indicating higher rates of depression among insecure individuals), parallel anxiety and depression analyses produced mean effects of similar significance and magnitude. When reviewed in tandem, these studies provide a greater understanding of the particular kinds of attachment representations that predispose individuals to internalizing symptomatology.

\section{Secure versus Insecure Attachment}

Contrary to our prediction, securely and insecurely attached individuals did not significantly differ in their anxiety symptoms. However, comparing the two insecure attachment subtypes to the secure attachment group revealed that preoccupied individuals, but not dismissing individuals, reported experiencing more anxiety symptoms than their secure counterparts. The current results suggest that insecure attachment subtypes are associated with different levels of risk for experiencing internalizing symptoms.

Securely attached individuals draw from past experiences with sensitive and responsive caregivers and are more confident in their ability to solicit support from close others than insecurely attached individuals (Seiffge-Krenke \& Beyers, 2005). It follows, then, that securely 
attached individuals may be less likely to experience prolonged distress about their safety in response to threatening stimuli than is often experienced by anxious individuals (Cassidy, 1995).

Compared to secure individuals, dismissing individuals are thought to experience elevated anxiety, but under-report these symptoms as a strategy to avoid them (Fortuna \& Roisman, 2008; Kobak \& Sceery, 1988; Pianta et al., 1996). Thus, dismissing individuals may only appear similar to securely attached individuals in analyses. Alternatively, dismissing individuals may actually experience low levels of distress given that they are well accustomed to avoid processing emotional stimuli altogether. Thus, it may also be that the observed similarity in anxiety symptoms experienced by dismissing and secure individuals may actually exist due to similar tendencies to perceive threats as less overwhelming than others.

We found several moderators of the association between insecure attachment subtypes and anxiety symptoms. Specifically, samples with a smaller percentage of White participants and predominantly low SES participants had significantly larger effect sizes than samples with larger percent of White participants and predominantly mid/high SES participants. Given that they expect that signaling their needs for support will result in the resolution of the distress, secure individuals are flexible and open to reporting distress if experienced (Kobak, Zajac, Herres, \& Krauthamer Ewing, 2015). The broader literature provides evidence that individuals who identify as ethnic minorities and individuals with low SES may experience more anxiety in general than their counterparts (Zvolensky, Garey, \& Bakhshaie, 2017); thus, securely attached individuals within these groups (i.e., minority, low SES) may be more inclined to report anxiety symptoms compared to the dismissing individuals, who tend to suppress expression of distress (Dagan, Facompré, et al., 2018; Roisman, 2006). When distress is low, as is potentially the case in mid/high SES and majority white samples, less anxiety is likely to be experienced by secure 
individuals, while dismissing individuals may still suppress its display even when experienced. Thus, secure and dismissing individuals in low risk samples may not differ significantly in their reported anxiety symptoms.

Of note, we found that the association between attachment classifications and anxiety symptoms decreased in magnitude over time, such that more recently published studies have smaller effect sizes than older studies. This phenomenon, also referred to as the "decline effect" (Ioannidis, 2005; Schooler, 2011), has been noted in other meta-analyses in the broader social sciences field (e.g., Molendijk et al., 2012) and the attachment field (Verhage et al., 2016). However, these results should be interpreted cautiously. For studies that reported on overlapping samples, we chose to use those which reported on larger samples or were published more recently over those reported on smaller samples and were published earlier. Thus, the year coded for moderation analyses may not have consistently represented the year in which data were collected.

\section{Dismissing versus Preoccupied Attachment}

Preoccupied individuals endorsed significantly more anxiety symptoms when directly compared to dismissing individuals. Previous research has suggested that preoccupied and dismissing individuals may show differences in information processing biases toward threat. For example, some have observed heightened physiological arousal among dismissing participants in response to AAI questions that provoke negative memories of caregivers (Dozier \& Kobak, 1992; Roisman, Tsai, \& Chiang, 2004; Roisman, 2007). This psychophysiological reactivity pattern may imply an initial, enhanced vigilance to, and processing of, the anxiety provoking stimuli (Hoehn-Saric \& McLeod, 2000; Hyde, Ryan, \& Waters, 2019). In addition, dismissing individuals often generate vague, idealizing statements to describe past experiences with primary 
caregivers. Their lack of recall for details around specific event memories may reflect an avoidance strategy which serves to minimize distress and suppress anxiety associated with threatening stimuli (Cassidy \& Kobak, 1988; Dozier \& Kobak, 1992; Hesse, 2016).

In contrast, preoccupied individuals readily engage with difficult attachment memories, often to excess. Indeed, they often appear irritable and preoccupied with a variety of perceived injustices perpetrated by primary caregivers (Hesse, 2016). This pattern of conversational discourse in the AAI is thought to reflect attentional fixation on negative attachment-related memories (Main, Kaplan, \& Cassidy, 1985). Similar to generally anxious adults who are engaged in prolonged attention to the source of threat (e.g., Fox, Russo, \& Dutton, 2002; Yiend \& Mathews, 2001), preoccupied individuals may attempt to alleviate anxiety via regaining a sense of control of threatening stimuli, thus making it more predictable and less distressing (Grupe \& Nitschke, 2013; Mineka \& Hendersen, 1985). Paradoxically, this strategy tends to prolong anxiety symptoms due to sustained conscious awareness of threat (Mogg \& Bradley, 2016). Thus, preoccupied individuals may be more vulnerable than dismissing adolescents and adults to experience prolonged and more severe anxiety symptoms.

Similar to the variables that moderated the link between secure versus dismissing attachment and anxiety, we found several factors that moderated the association between insecure attachment subtypes and anxiety symptoms. Specifically, majority non-White, predominantly low SES, and author-identified high-risk samples evidenced significantly larger effect sizes than majority White, mid/high SES, and low-risk samples. These findings may suggest that other chronic stressors_-such as being a minority or low SES group member (Zvolensky et al., 2017)—exacerbate the effect of preoccupied (versus dismissing) attachment on anxiety symptoms. Cumulatively, risk factors pose additional stressors that high risk 
preoccupied individuals may face compared to their low risk counterparts, and thus increase their experience of anxiety. Dismissing individuals' deactivating strategy, however, may be equally effective in avoiding anxiety even when operating in high risk environment, contributing to the larger observed difference in anxiety symptoms between the insecure attachment subtype groups in studies of high-risk samples.

We also found that the time between assessments of attachment representations and anxiety symptoms moderated the link between insecure attachment subtypes and anxiety symptoms. Specifically, the average effect size of studies for which the time between AAI administration and anxiety assessment was greater than one month was near zero $(d=.04)$, whereas the effect size for studies with attachment and anxiety assessments administered concurrently (less than 1 month apart) was moderate to large $(d=0.62)$. Given the high variability in the amount of time between assessments among studies categorized as "nonconcurrent" in this moderator analyses (between 1 month and 10 years), it may be the case that anxiety symptoms and/or attachment classifications changed from one assessment time point to the next, leading to null results within this category.

\section{Organized versus Unresolved Attachment}

Our findings indicated that individuals classified as unresolved tended to report more anxiety symptoms than those classified as any of the organized attachment patterns (i.e., individuals who are not classified with a primary unresolved status). Heightened anxiety symptomatology in individuals who were classified as unresolved with respect to loss and/or abuse is consistent with trauma research, indicating that individuals who were exposed to childhood trauma tend to experience more anxiety symptoms (Marusak, Martin, Etkin, \& Thomason, 2015; Shalev, Liberzon, \& Marmar, 2017). 
Our exploratory analyses revealed that unresolved/preoccupied individuals endorsed significantly more anxiety symptoms than unresolved/dismissing individuals. This result suggests that unresolved status as coded via the AAI may not significantly affect anxiety symptomatology over and above insecure attachment patterns. These results are in line with evidence suggesting that preoccupied and unresolved attachment representations load on a common factor (Haltigan, Roisman, \& Haydon, 2014; Roisman \& Cicchetti, 2017). It may thus be the case that the two attachment classifications are too strongly correlated to produce differential correlates as they may not be psychologically distinct phenomena.

\section{Clinical Implications}

The current findings suggest that attachment patterns are important in understanding the interpersonal aspects of anxiety symptoms. Given that attachment patterns may be conceptualized as a lens through which one processes interpersonal information and likely influence affect regulatory capacities during times of distress (Bowlby, 1988; Daniel, 2006), targeting attachment representations through clinical intervention may prove useful in alleviating symptoms of anxiety. By increasing clinicians' sensitivity to the centrality of attachment representations to psychopathological symptoms, including anxiety, treatment effectiveness may be enhanced (Slade, 1999).

Attachment representations are thought to reflect past repeated interactions with attachment figures (Haydon, Collins, Salvatore, Simpson, \& Roisman, 2012; Roisman et al., 2017; Steele et al., 2014). As attachment-relevant experiences become consolidated, relational schemas begin to shape beliefs about whether bids for support are likely to be recognized and needs effectively met (Bretherton \& Munholland, 2008; Waters \& Roisman, 2019). Accordingly, cognitive restructuring of client expectations regarding soliciting support when 
anxious may be an effective strategy for reducing anxiety symptoms among preoccupied and unresolved individuals. Moreover, an attachment-based clinical approach entails using the therapeutic alliance formed between clients and therapists as a safe interpersonal context from which clients can explore their ability to effectively communicate their distress with, and being effectively soothed by the therapist. Becoming aware of this and targeting less than optimal relational patterns through repeated interactions with the therapist may prove clinically useful when attempting to solicit effective support from others when experiencing anxiety (Holmes \& Slade, 2018).

In addition to addressing the relational schemas in individual psychotherapy, prevention efforts can target attachment representations pre-adolescence. To this end, attachment-based interventions in infancy and childhood have shown promising results in reducing disorganized and insecure attachment patterns (for a review of studies, see Bakermans-Kranenburg, Van IJzendoorn, \& Juffer, 2003; Facompré, Bernard, \& Waters, 2017). Although studies of attachment-based interventions have yet to provide longitudinal evidence for effectively preventing or decreasing anxiety symptoms, increases in attachment security may aid in such efforts.

\section{Limitations and Future Research}

Several limitations should be considered when interpreting our results. First, one cannot infer causality when interpreting the links between attachment patterns and anxiety symptoms delineated here. Experimental clinical trials that modify attachment-related constructs may offer evidence of casual associations between attachment patterns and anxiety symptoms.

Second, given that most studies in the current meta-analysis recruited non-clinical samples, the overall effect sizes reported here may not reflect the magnitude of the association 
between attachment representations and clinically-diagnosed anxiety disorders. Instead, one may conceive attachment representations as aspects of early developed (mal)adaptation to one's interpersonal environment (e.g., primary caregivers), which may increase or decrease the vulnerability to experiencing anxiety symptoms later in life. Further, research is needed to examine contextual and individual moderators that were not possible to test in the current investigation and which may interact with attachment representations to better predict anxiety in adolescent and adulthood. For example, exposure to child maltreatment and other adverse experiences (Felitti et al., 1998; Scott, Smith, \& Ellis, 2010), susceptibility to environmental conditions in general (Ellis, Boyce, Belsky, Bakermans-Kranenburg, \& Van IJzendoorn, 2011), and personality traits (Brandes \& Bienvenu, 2006) may be of interest in this regard. Relatedly, examining the mechanisms through which attachment patterns may affect anxiety symptoms, such as emotion regulation capacities (Mikulincer, Shaver, \& Pereg, 2003; Esbjørn et al., 2012) is of great importance as well.

Third, this study included only studies that used the AAI for assessing attachment. In doing so, we excluded studies that examined attachment styles in the context of romantic relationships via self-report measures such as the Experiences in Close Relationships (ECR; Brennan, Clark, \& Shaver, 1998) and the Relationship Scales Questionnaire (RSQ; Griffin \& Bartholomew, 1994). Although the AAI and self-report measures are directed at assessing different attachment figures (primary caregivers versus romantic partners, respectively), and were shown to be only weakly associated (Roisman et al., 2007), an outstanding question is to what degree do studies using these two instruments converge when assessing links between attachment and anxiety symptoms. Additionally, one may ask to what degree attachment selfreport measures predict anxiety symptoms above and beyond classifications on the AAI. Future 
research that focuses on the link between post-childhood attachment and anxiety symptoms using both AAI and self-report measures would clearly help to answer such questions.

Fourth, given that we focused on post-childhood attachment representations, we are limited in our ability to draw conclusions about developmental trajectories in anxiety symptoms stemming from attachment representations early in life. In fact, the results reported here demonstrating that individuals with hyperactivating attachment strategies (i.e., preoccupied) report higher anxiety symptoms than those with deactivating attachment strategies (i.e., dismissing), stand in contrast to similar meta-analyses conducted with children. Two large scale meta-analyses (Groh et al., 2012; Madigan et al., 2013) reported associations between insecure attachment patterns in infancy and early childhood and anxiety in childhood that are opposite in direction to what we found here. That is, children classified as insecure-avoidant (parallel to adult insecure-dismissing attachment), but not those classified as insecure-resistant (parallel to adult preoccupied), had more anxiety symptoms during childhood than their secure counterparts. This paradox, which was noted before regarding depression symptoms (Dagan \& Bernard, 2019; Dagan, Facompré, et al., 2018), suggests that the nature of the association between attachment patterns and internalizing symptoms may shift across developmental periods. Future research should attempt to explain the paradoxical findings using a prospective, multi-method study focusing and such links across the lifespan.

\section{Conclusion}

This meta-analysis is the first to examine the link between adult attachment representation as measured in the AAI and anxiety symptoms across a diverse range of clinical and non-clinical populations. The findings suggest that insecure attachment patterns may be differentially linked to anxiety symptoms. In particular, preoccupied individuals showed 
elevated rates of anxiety when compared both to secure and dismissing individuals. We also present strong evidence that unresolved attachment representations increase risk for anxiety symptoms, but this effect may be primarily driven by preoccupied attachment representation. We encourage increased clinical attention to the interpersonal aspect of anxiety. Specifically, careful attention should be paid to the support soliciting strategies which underlie preoccupied and unresolved individuals' experience of anxiety. These strategies may shape ineffective support soliciting behaviors, which in themselves may function as risk factors to exacerbating anxiety symptoms. Lastly, we encourage future research to thoroughly examine the mechanisms through which attachment patterns confer risk for or offer protection from the development and maintenance of anxiety symptoms. 


\section{Authorship}

O.D, C. R. F., and K. B. designed the study. O. D. and C. R. F. conducted the systematic literature search, under the supervision of Bernard. O.D., C. R. F., and M. D. N. acquired data from authors, under the supervision of K. B. and G. I. R.. O. D. and C. R. F. coded data. C. R. F. conducted the statistical analyses. O.D, C. R. F., and K. B. wrote the first draft of the manuscript and all authors contributed to and have approved the final manuscript. 


\section{Acknowledgments}

We would like to thank the authors whose data were included in this meta-analytic review. 


\section{References}

References marked with an asterisk indicate studies included in the meta-analysis.

*Ablow, J. C., Marks, A. K., Shirley Feldman, S., \& Huffman, L. C. (2013). Associations between first-time expectant women's representations of attachment and their physiological reactivity to infant cry. Child Development, 84(4), 1373-1391. https://doi.org/10.1111/cdev.12135

*Adam, E. K., Gunnar, M. R., \& Tanaka, A. (2004). Adult attachment, parent emotion, and observed parenting behavior: Mediator and moderator models. Child Development, 75(1), 110-122. https://doi.org/10.1111/j.1467-8624.2004.00657.x

Ainsworth, M. D. S. (1983). Patterns of infant-mother attachment as related to maternal care: Their early history and their contribution to continuity. In D. Magnusson \& V. L. Alle (Eds.), Human development: An interactional perspective (pp. 35-55). New York: Academic Press.

Ainsworth, M. D. S., Blehar, M. C., Waters, E., \& Wall, S. N. (2015). Patterns of attachment: A psychological study of the strange situation. Patterns of Attachment: A Psychological Study of the Strange Situation. Hillsdale, New Jersey: Erlbaum. https://doi.org/10.4324/9780203758045

Alden, L. E., \& Taylor, C. T. (2010). Interpersonal processes in social anxiety disorder. Interpersonal processes in the anxiety disorders: Implications for understanding psychopathology and treatment. Washington, DC, US: American Psychological Association. https://doi.org/10.1037/12084-005

Angst, J., Merikangas, K. R., \& Preisig, M. (1997). Subthreshold syndromes of depression and anxiety in the community. The Journal of Clinical Psychiatry, 58(suppl 8), 6-10. 
Atkinson, L., \& Goldberg, S. (2003). Attachment issues in psychopathology and intervention. Routledge.

*Atkinson, L., Leung, E., Goldberg, S., Benoit, D., Poulton, L., Myhal, N., ... Kerr, S. (2009). Attachment and selective attention: Disorganization and emotional Stroop reaction time. Development and Psychopathology, 21(1), 99-126.

https://doi.org/10.1017/S0954579409000078

*Bakermans-Kranenburg, M. J., van IJzendoorn, M. H., Caspers, K., \& Philibert, R. (2011).

DRD4 genotype moderates the impact of parental problems on unresolved loss or trauma. Attachment \& Human Development, 13(3), 253-269.

https://doi.org/10.1080/14616734.2011.562415

Bakermans-Kranenburg, M. J., \& van IJzendoorn, M. H. (2009). The first 10,000 Adult Attachment Interviews: Distributions of adult attachment representations in clinical and non-clinical groups. Attachment \& Human Development, 11(3), 223-263. https://doi.org/10.1080/14616730902814762

Bakermans-Kranenburg, M. J., van IJzendoorn, M. H., \& Juffer, F. (2003). Less is more: Metaanalyses of sensitivity and attachment interventions in early childhood. Psychological Bulletin, 129(2), 195-215. https://doi.org/10.1037/0033-2909.129.2.195

Balázs, J., Miklósi, M., Keresztény, Á., Hoven, C. W., Carli, V., Wasserman, C., ... Cosman, D. (2013). Adolescent subthreshold-depression and anxiety: Psychopathology, functional impairment and increased suicide risk. Journal of Child Psychology \& Psychiatry, 54(6), $670-677$.

*Balenzano, C., Coppola, G., Cassibba, R., \& Moro, G. (2018). Pre-adoption adversities and adoptees' outcomes: The protective role of post-adoption variables in an italian experience 
of domestic open adoption. Children and Youth Services Review, 85, 307-318. https://doi.org/10.1016/j.childyouth.2018.01.012

Bandelow, B., Reitt, M., Röver, C., Michaelis, S., Görlich, Y., \& Wedekind, D. (2015). Efficacy of treatments for anxiety disorders: a meta-analysis. International Clinical Psychopharmacology, 30(4), 183-192.

Bar-Haim, Y., Dan, O., Eshel, Y., \& Sagi-Schwartz, A. (2007). Predicting children's anxiety from early attachment relationships. Journal of Anxiety Disorders, 21(8), 1061-1068. https://doi.org/https://doi.org/10.1016/j.janxdis.2006.10.013

Bar-Haim, Y., Lamy, D., Pergamin, L., Bakermans-Kranenburg, M. J., \& van IJzendoorn, M. H. (2007). Threat-related attentional bias in anxious and nonanxious individuals: A metaanalytic study. Psychological Bulletin, 133(1), 1-24. https://doi.org/10.1037/00332909.133.1.1

*Bernstein, R. E. (2016). Identifying perinatal predictors of disorganized infant-mother attachment: An important step toward connecting families with appropriate early interventions. Unpublished doctoral dissertation, University of Oregon.

*Blumberg, P. (1997). Adult attachment and the organization of affective experience. Unpublished doctoral dissertation, The University of Michigan.

Bögels, S. M., Knappe, S., \& Clark, L. A. (2013). Adult separation anxiety disorder in DSM-5. Clinical Psychology Review, 33(5), 663-674. https://doi.org/https://doi.org/10.1016/j.cpr.2013.03.006

*Borelli, J. L., Brugnera, A., Zarbo, C., Rabboni, M., Bondi, E., Tasca, G. A., \& Compare, A. (2019). Attachment comes of age: Adolescents' narrative coherence and reflective functioning predict well-being in emerging adulthood. Attachment \& Human Development, 
21(4), 332-351. https://doi.org/10.1080/14616734.2018.1479870

*Borelli, J. L., David, D. H., Rifkin-Graboi, A., Sbarra, D. A., Mehl, M. R., \& Mayes, L. C. (2013). Language use in the Adult Attachment Interview: Evidence for attachment-specific emotion regulation. Personal Relationships, 20(1), 23-37. https://doi.org/10.1111/j.14756811.2012.01394.x

Borenstein, M., Hedges, L. V, Higgins, J. P. T., \& Rothstein, H. R. (2011). Introduction to metaanalysis. John Wiley \& Sons.

Bosquet, M., \& Egeland, B. (2006). The development and maintenance of anxiety symptoms from infancy through adolescence in a longitudinal sample. Development and Psychopathology, 18(2), 517-550. https://doi.org/10.1017/S0954579406060275

Bowlby, J. (1951). Maternal care and mental health. World Health Organization Monograph Series (Serial No. 2).

Bowlby, J. (1973). Attachment and Loss: Vol. 2. Separation: Anxiety and anger. New York, NY: Basic Books.

Bowlby, J. (1988). A secure base: Clinical applications of attachment theory. London: Routledge.

Brandes, M., \& Bienvenu, O. J. (2006). Personality and anxiety disorders. Current Psychiatry Reports, 8(4), 263-269. https://doi.org/10.1007/s11920-006-0061-8

Brennan, K. A., Clark, C. L., \& Shaver, P. (1998). Self-report measures of adult romantic attachment. Attachment Theory and Close Relationships, 46-76.

Bretherton, I. (1985). Attachment theory: Retrospect and prospect. Monographs of the Society for Research in Child Development, 50(1-2), 3-35. https://doi.org/http://dx.doi.org.libproxy.newschool.edu/10.2307/3333824 
Bretherton, I. (1991). Pouring new wine into old bottles: The social self as internal working model. In M. R. Gunnar \& L. A. Sroufe (Eds.), Minnesota symposia in child psychology: Self processes in development (pp. 1-41). Hillsdale, NJ: Erlbaum.

Bretherton, I. (1992). The origins of attachment theory. Developmental Psychology, 28(28), 759775. https://doi.org/10.1037/0012-1649.28.5.759

Bretherton, I., \& Munholland, K. A. (2008). Internal working models in attachment relationships: Elaborating a central construct in attachment theory. In J. Cassidy \& P. R. Shaver (Eds.), Handbook of attachment: Theory, research and clinical applications (2nd ed., pp. 102-127). New York, NY: Guilford Press.

Britton, J. C., Lissek, S., Grillon, C., Norcross, M. A., \& Pine, D. S. (2011). Development of anxiety: The role of threat appraisal and fear learning. Depression and Anxiety, 28(1), 5-17. https://doi.org/10.1002/da.20733

Brumariu, L. E., \& Kerns, K. A. (2013). Pathways to anxiety: Contributions of attachment history, temperament, peer competence, and ability to manage intense emotions. Child Psychiatry \& Human Development, 44(4), 504-515. https://doi.org/10.1007/s10578-0120345-7

Brumariu, L. E., Obsuth, I., \& Lyons-Ruth, K. (2013). Quality of attachment relationships and peer relationship dysfunction among late adolescents with and without anxiety disorders. Journal of Anxiety Disorders, 27(1), 116-124. https://doi.org/10.1016/j.janxdis.2012.09.002

Bubier, J. L., \& Drabick, D. A. G. (2009). Co-occurring anxiety and disruptive behavior disorders: The roles of anxious symptoms, reactive aggression, and shared risk processes. Clinical Psychology Review, 29(7), 658-669.

*Busch, A. L., Cowan, P. A., \& Cowan, C. P. (2008). Unresolved loss in the Adult Attachment 
Interview: Implications for marital and parenting relationships. Development and Psychopathology, 20(02), 717-735. https://doi.org/10.1017/S0954579408000345

Carlson, E. A., \& Sroufe, L. A. (1995). Contribution of attachment theory to developmental psychopathology. In D. Cicchetti \& D. Cohen (Eds.), Developmental Psychopathology: Vol. 1. Theory and methods (pp. 581-616). Oxford: Wiley.

Carter, M. M., Mitchell, F. E., \& Sbrocco, T. (2012). Treating ethnic minority adults with anxiety disorders: Current status and future recommendations. Journal of Anxiety Disorders, 26(4), 488-501.

*Cary, H. H. (2000). Attachment status and post-divorce adjustment in women. Unpublished doctoral dissertation, The California School of Professional Psychology.

Cassidy, J. (1995). Attachment and generalized anxiety disorder. In D. Cicchetti \& S. L. Toth (Eds.), Rochester symposium on developmental psychopathology, Vol. 6. Emotion, cognition, and representation (pp. 343-370). Rochester, NY, US: University of Rochester Press.

Cassidy, J., \& Kobak, R. (1988). Avoidance and its relation to other defensive processes. In J. Belsky \& T. Nezworski (Eds.), Clinical implications of attachment theory (pp. 300-323). Hillsdale, NJ: Erlbaum.

Cisler, J. M., \& Koster, E. H. W. (2010). Mechanisms of attentional biases towards threat in anxiety disorders: An integrative review. Clinical Psychology Review, 30(2), 203-216. https://doi.org/https://doi.org/10.1016/j.cpr.2009.11.003

Colonnesi, C., Draijer, E. M., Jan JM Stams, G., Van der Bruggen, C. O., Bögels, S. M., \& Noom, M. J. (2011). The relation between insecure attachment and child anxiety: A metaanalytic review. Journal of Clinical Child \& Adolescent Psychology, 40(4), 630-645. 
Cosgrove, V. E., Rhee, S. H., Gelhorn, H. L., Boeldt, D., Corley, R. C., Ehringer, M. A., ... Hewitt, J. K. (2011). Structure and etiology of co-occurring internalizing and externalizing disorders in adolescents. Journal of Abnormal Child Psychology, 39(1), 109-123. https://doi.org/10.1007/s10802-010-9444-8

Crocq, M. A. (2015). A history of anxiety: From Hippocrates to DSM. Dialogues in Clinical Neuroscience, 17(3), 319-325.

Crocq, M. A. (2017). The history of generalized anxiety disorder as a diagnostic category. Dialogues in Clinical Neuroscience, 19(2), 107-116. Retrieved from https://www.ncbi.nlm.nih.gov/pubmed/28867935

*Dagan, O., Asok, A., Steele, H., Steele, M., \& Bernard, K. (2018). Attachment security moderates the link between adverse childhood experiences and cellular aging. Development and Psychopathology, 30(4), 1211-1223. https://doi.org/10.1017/S0954579417001705

Dagan, O., \& Bernard, K. (2019, September 30). The paradox of insecure attachment and depressive symptoms across the lifespan: Towards an integrative view. https://doi.org/10.31219/osf.io/jbsth

Dagan, O., Facompré, C. R., \& Bernard, K. (2018). Adult attachment representations and depressive symptoms: A meta-analysis. Journal of Affective Disorders, 236, 274-290. https://doi.org/https://doi.org/10.1016/j.jad.2018.04.091

Daniel, S. I. F. (2006). Adult attachment patterns and individual psychotherapy: A review. Clinical Psychology Review, 26(8), 968-984. https://doi.org/10.1016/j.cpr.2006.02.001

*Dawson, A. E., Allen, J. P., Marston, E. G., Hafen, C. A., \& Schad, M. M. (2014). Adolescent insecure attachment as a predictor of maladaptive coping and externalizing behaviors in emerging adulthood. Attachment and Human Development, 16(5), 462-478. 
https://doi.org/10.1080/14616734.2014.934848

Derogatis, L. R., \& Cleary, P. A. (1977). Confirmation of the dimensional structure of the SCL90: A study in construct validation. Journal of Clinical Psychology, 33(4), 981-989.

Diamond, L. M., \& Aspinwall, L. G. (2003). Emotion regulation across the life span: An integrative perspective emphasizing self-regulation, positive affect, and dyadic processes. Motivation and Emotion, 27(2), 125-156. https://doi.org/10.1023/A:1024521920068

Dozier, M., \& Kobak, R. R. (1992). Psychophysiology in attachment interviews: Converging evidence for deactivating strategies. Child Development, 63(6), 1473-1480. https://doi.org/10.1111/1467-8624.ep9308195014

Duschinsky, R. (2020). Cornerstones of attachment research. Oxford: Oxford University Press.

Duval, S. J., \& Tweedie, R. L. (2000a). A nonparametric "trim and fill” method of accounting for publication bias in meta-analysis. Journal of the American Statistical Association, 95(449), 89-98. https://doi.org/10.2307/2669529

Duval, S. J., \& Tweedie, R. L. (2000b). Trim and fill: A simple funnel-plot-based method of testing and adjusting for publication bias in meta-analysis. Biometrics, 56(2), 455-463. https://doi.org/10.1111/j.0006-341X.2000.00455.x

Eaton, N. R., Krueger, R. F., Markon, K. E., Keyes, K. M., Skodol, A. E., Wall, M., ... Grant, B. F. (2013). The structure and predictive validity of the internalizing disorders. Journal of Abnormal Psychology, 122(1), 86-92. https://doi.org/10.1037/a0029598

*Ehrlich, K. B., Cassidy, J., \& Dykas, M. J. (2011). Reporter discrepancies among parents, adolescents, and peers: Adolescent attachment and informant depressive symptoms as explanatory factors. Child Development, 82(3), 999-1012. https://doi.org/10.1111/j.14678624.2010.01530.x 
Ellis, B. J., Boyce, W. T., Belsky, J., Bakermans-Kranenburg, M. J., \& van IJzendoorn, M. H. (2011). Differential susceptibility to the environment: An evolutionaryneurodevelopmental theory. Development and Psychopathology, 23(1), 7-28. https://doi.org/10.1017/S0954579410000611

Esbjørn, B. H., Bender, P. K., Reinholdt-Dunne, M. L., Munck, L. A., \& Ollendick, T. H. (2012). The development of anxiety disorders: Considering the contributions of attachment and emotion regulation. Clinical Child and Family Psychology Review, 15(2), 129-143.

Facompré, C. R., Bernard, K., \& Waters, T. E. A. (2017). Effectiveness of interventions in preventing disorganized attachment: A meta-analysis. Development and Psychopathology, 1-11. https://doi.org/10.1017/S0954579417000426

Felitti, V. J., Anda, R. F., Nordenberg, D., Williamson, D. F., Spitz, A. M., Edwards, V., ... Marks, J. S. (1998). Relationship of childhood abuse and household dysfunction to many of the leading causes of death in adults: The adverse childhood experiences (ACE) study. American Journal of Preventive Medicine, 14(4), 245-258. https://doi.org/10.1016/S07493797(98)00017-8

Ferreri, F., Lapp, L. K., \& Peretti, C.-S. (2011). Current research on cognitive aspects of anxiety disorders. Current Opinion in Psychiatry, 24(1), 49-54. https://doi.org/10.1097/YCO.0b013e32833f5585

*Finger, B. (2006). Exploring the intergenerational transmission of attachment disorganization. Unpublished doctoral dissertation, Thr University of Chicago.

Fonagy, P., Leigh, T., Steele, M., Steele, H., Kennedy, R., Mattoon, G., ... Gerber, A. (1996). The relation of attachment status, psychiatric classification, and response to psychotherapy. Journal of Consulting and Clinical Psychology, 64(1), 22-31. https://doi.org/10.1037/0022- 
006X.64.1.22

Fortuna, K., \& Roisman, G. I. (2008). Insecurity, stress, and symptoms of psychopathology: Contrasting results from self-reports versus interviews of adult attachment. Attachment \& Human Development, 10(1), 11-28. https://doi.org/10.1080/14616730701868571

*Fortuna, K., Roisman, G. I., Haydon, K. C., Groh, A. M., \& Holland, A. S. (2011). Attachment states of mind and the quality of young adults' sibling relationships. Developmental Psychology, 47(5), 1366-1373. https://doi.org/10.1037/a0024393

Fox, E., Russo, R., \& Dutton, K. (2002). Attentional bias for threat: Evidence for delayed disengagement from emotional faces. Cognition and Emotion, 16(3), 355-379. https://doi.org/10.1080/02699930143000527

Garnefski, N., \& Kraaij, V. (2018). Specificity of relations between adolescents' cognitive emotion regulation strategies and symptoms of depression and anxiety. Cognition and Emotion, 32(7), 1401-1408. https://doi.org/10.1080/02699931.2016.1232698

George, C., Kaplan, N., \& Main, M. (1985). Adult attachment interview. Unpublished manuscript. Regents of the University of California, Berkeley, CA.

*Gralinski-Bakker, J. H., Hauser, S. T., Stott, C., Billings, R. L., \& Allen, J. P. (2004). Markers of resilience and risk: Adult lives in a vulnerable population. Research in Human Development, 1(4), 291-326. https://doi.org/10.1207/s15427617rhd0104_4

Griffin, D., \& Bartholomew, K. (1994). Models of the slf and ther: Fundamental dimoensions underlying measures of adult attachment. Journal of Personality and Social Psychology, 67(3), 430-445. https://doi.org/10.1037/0022-3514.67.3.430

Groh, A. M., Roisman, G. I., van IJzendoorn, M. H., Bakermans-Kranenburg, M. J., \& Fearon, R. P. (2012). The significance of insecure and disorganized attachment for children's 
internalizing symptoms: A meta-analytic study. Child Development, 83(2), 591-610. https://doi.org/10.1111/j.1467-8624.2011.01711.x

Gross, J. J. (2015). Emotion regulation: Current status and future prospects. Psychological Inquiry, 26(1), 1-26. https://doi.org/10.1080/1047840X.2014.940781

Grupe, D. W., \& Nitschke, J. B. (2013). Uncertainty and anticipation in anxiety: An integrated neurobiological and psychological perspective. Nature Reviews. Neuroscience, 14(7), 488501. https://doi.org/10.1038/nrn3524

Haltigan, J. D., Roisman, G. I., \& Haydon, K. C. (2014). II. The latent structure of the adult attachment interview: Exploratory and confirmatory evidence. Monographs of the Society for Research in Child Development, 79(3), 15-35. https://doi.org/10.1111/mono.12111

Haslam, N., Holland, E., \& Kuppens, P. (2012). Categories versus dimensions in personality and psychopathology: a quantitative review of taxometric research. Psychological Medicine, 42(5), 903-920. https://doi.org/DOI: 10.1017/S0033291711001966

Haydon, K. C., Collins, W. A., Salvatore, J. E., Simpson, J. A., \& Roisman, G. I. (2012). VII. Shared and distinctive origins and correlates of adult attachment representations: The developmental organization of romantic functioning. Child Development, 83(5), 16891702. https://doi.org/10.1111/j.1467-8624.2012.01801.x

*Haydon, K. C., Roisman, G. I., Owen, M. T., Booth-Laforce, C., \& Cox, M. J. (2014). VII. Shared and distinctive antecedents of adult attachment interview state-of-mind and inferredexperience dimensions. Monographs of the Society for Research in Child Development, 79(3), 108-125. https://doi.org/10.1111/mono.12116

Helmchen, H., \& Linden, M. (2000). Subthreshold disorders in psychiatry: Clinical reality, methodological artifact, and the double-threshold problem. Comprehensive Psychiatry, 
41(2, Supplement 1), 1-7. https://doi.org/https://doi.org/10.1016/S0010-440X(00)80001-2

Hesse, E. (2016). The Adult Attachment Interview: Protocol, method of analysis, and empirical studies: 1985-2015. In J. Cassidy \& P. R. Shaver (Eds.), Handbook of attachment: Theory, research, and clinical applications (3rd ed., pp. 553-597). New York, NY: Guilford Press.

Hesse, Erik, \& Main, M. (2006). Frightened, threatening, and dissociative parental behavior in low-risk samples: Description, discussion, and interpretations. Development and Psychopathology, 18(2), 309-343. https://doi.org/10.1017/S0954579406060172

Hoehn-Saric, R., \& McLeod, D. R. (2000). Anxiety and arousal: Physiological changes and their perception. Journal of Affective Disorders, 61(3), 217-224.

*Holland, A. S., \& Roisman, G. I. (2010). Adult attachment security and young adults' dating relationships over time: Self-reported, observational, and physiological evidence. Developmental Psychology, 46(2), 552-557. https://doi.org/10.1037/a0018542

Holmes, J., \& Slade, A. (2018). Attachment in therapeutic practice. Thousand Oaks, CA, US: Sage Publications, Inc.

*Hughes, P., Turton, P., Hopper, E., McGauley, G. A., \& Fonagy, P. (2004). Factors associated with the unresolved classification of the Adult Attachment Interview in women who have suffered stillbirth. Development and Psychopathology, 16(1), 215-230.

https://doi.org/10.1017/S0954579404044487

Hyde, J., Ryan, K. M., \& Waters, A. M. (2019). Psychophysiological Markers of fear and anxiety. Current Psychiatry Reports, 21(7), 56.

IntHout, J., Ioannidis, J. P. A., Rovers, M. M., \& Goeman, J. J. (2016). Plea for routinely presenting prediction intervals in meta-analysis. BMJ Open, 6(7), e010247. https://doi.org/10.1136/bmjopen-2015-010247 
Ioannidis, J. P. A. (2005). Contradicted and initially stronger effects in highly cited clinical research. JAMA, 294(2), 218-228.

*Jones-Mason, K., Allen, I. E., Bush, N., \& Hamilton, S. (2016). Epigenetic marks as the link between environment and development: examination of the associations between attachment, socioeconomic status, and methylation of the SLC6A4 gene. Brain and Behavior, 6(7), e00480.

Kerns, K. A., \& Brumariu, L. E. (2014). Is insecure parent-child attachment a risk factor for the development of anxiety in childhood or adolescence? Child Development Perspectives, 8(1), 12-17. https://doi.org/10.1111/cdep.12054

Kessler, R. C., Petukhova, M., Sampson, N. A., Zaslavsky, A. M., \& Wittchen, H. (2012). Twelve-month and lifetime prevalence and lifetime morbid risk of anxiety and mood disorders in the United States. International Journal of Methods in Psychiatric Research, 21(3), 169-184.

Kobak, R., Zajac, K., Herres, J., \& Krauthamer Ewing, E. S. (2015). Attachment based treatments for adolescents: The secure cycle as a framework for assessment, treatment and evaluation. Attachment \& Human Development, 17(2), 220-239.

*Kobak, R., Zajac, K., \& Smith, C. (2009). Adolescent attachment and trajectories of hostileimpulsive behavior: Implications for the development of personality disorders. Development and Psychopathology, 21(3), 839-851. https://doi.org/10.1017/S0954579409000455

Kobak, R. R. (1993). The Adult Attachment Interview Q-Set. Unpublished document, University of Delaware, Newark.

*Kobak, R. R., \& Sceery, A. (1988). Attachment in late adolescence: Working models, affect regulation, and representations of self and others. Child Development, 59(1), 135-146. 
https://doi.org/10.2307/1130395

Kobak, R. R., Cole, H. E., Ferenz-Gillies, R., Fleming, W. S., \& Gamble, W. (1993). Attachment and emotion regulation during mother-teen problem solving: A control theory analysis. Child Development, 64(1), 231-245. https://doi.org/10.2307/1131448

*Koren-Karie, N., \& Getzler-Yosef, R. (2018). Mothers' insightfulness regarding their children's inner world: Associations with mothers' history of sexual abuse and lack of resolution of the trauma. Attachment \& Human Development. https://doi.org/10.1080/14616734.2018.1472287

Kotov, R., Waszczuk, M. A., Krueger, R. F., Forbes, M. K., Watson, D., Clark, L. A., ... Zimmerman, M. (2017). The hierarchical taxonomy of psychopathology (HiTOP): A dimensional alternative to traditional nosologies. Journal of Abnormal Psychology, 126(4), 454-477. https://doi.org/10.1037/abn0000258

Krueger, R. F., \& Markon, K. E. (2006). Reinterpreting comorbidity: A model-based approach to understanding and classifying psychopathology. Annual Review of Clinical Psychology, 2(1), 111-133. https://doi.org/10.1146/annurev.clinpsy.2.022305.095213

*Kuipers, G. S., van Loenhout, Z., van der Ark, L. A., \& Bekker, M. H. J. (2016). Attachment insecurity, mentalization and their relation to symptoms in eating disorder patients. Attachment \& Human Development, 18(3), 250-272. https://doi.org/10.1080/14616734.2015.1136660

Lipsey, M. W., \& Wilson, D. B. (2001). Practical meta-analysis. Sage Publications, Inc. Madigan, S., Atkinson, L., Laurin, K., \& Benoit, D. (2013). Attachment and internalizing behavior in early childhood: A meta-analysis. Developmental Psychology, 49(4), 672-689. https://doi.org/10.1037/a0028793 
Main, M. (1981). Avoidance in the service of attachment: A working paper. In K. Immelman, G. Barlow, L. Petrinovich, \& M. Main (Eds.), Behavioral development: The Bielfeld interdisciplinary project (pp. 651-693). New York: Cambridge University Press.

Main, M. (1990). Cross-cultural studies of attachment organization: Recent studies, changing methodologies, and the concept of conditional strategies. Human Development, 33(1), 4661.

Main, M. (2000). The organized categories of infant, child, and adult attachment: Flexible vs. inflexible attention under attachment-related stress. Journal of the American Psychoanalytic Association, 48(4), 1055-1096; discussion 1175-1187. https://doi.org/10.1177/00030651000480041801

Main, M., \& Goldwyn, R. (1998). Adult attachment scoring and classification system. Unpublished Manual, Berkeley: University of California at Berkeley.

Main, M., Kaplan, N., \& Cassidy, J. (1985). Security in infancy, childhood, and adulthood: A move to the level of representation. Monographs of the Society for Research in Child Development, 50(1-2), 66-104. https://doi.org/http://dx.doi.org.libproxy.newschool.edu/10.2307/3333827

Manassis, K. (2001). Child-parent relations: Attachment and anxiety disorders. In W. K. Silverman \& P. D. A. Treffers (Eds.), Anxiety disorders in children and adolescents: Research, assessment, and intervention (pp. 255-272). Cambridge, UK: Cambridge University Press.

Manassis, K., Bradley, S., Goldberg, S., Hood, J., \& Swinson, R. P. (1994). Attachment in mothers with anxiety disorders and their children. Journal of the American Academy of Child \& Adolescent Psychiatry, 33(8), 1106-1113. https://doi.org/10.1097/00004583- 
199410000-00006

Marusak, H. A., Martin, K. R., Etkin, A., \& Thomason, M. E. (2015). Childhood trauma exposure disrupts the automatic regulation of emotional processing. Neuropsychopharmacology, 40(5), 1250.

McEwen, B. S., Bowles, N. P., Gray, J. D., Hill, M. N., Hunter, R. G., Karatsoreos, I. N., \& Nasca, C. (2015). Mechanisms of stress in the brain. Nature Neuroscience, 18(10), 13531363. https://doi.org/10.1038/nn.4086

McLean, C. P., Asnaani, A., Litz, B. T., \& Hofmann, S. G. (2011). Gender differences in anxiety disorders: Prevalence, course of illness, comorbidity and burden of illness. Journal of Psychiatric Research, 45(8), 1027-1035. https://doi.org/https://doi.org/10.1016/j.jpsychires.2011.03.006

Mineka, S., \& Zinbarg, R. (2006). A contemporary learning theory perspective on the etiology of anxiety disorders: It's not what you thought it was. American Psychologist, 61(1), 10-26. https://doi.org/10.1037/0003-066X.61.1.10

Mikulincer, M., \& Shaver, P. R. (2012). An attachment perspective on psychopathology. World Psychiatry, 11(1), 11-15. https://doi.org/10.1037/14498-005

Mikulincer, M., Shaver, P. R., \& Pereg, D. (2003). Attachment theory and affect regulation: The dynamics, development, and cognitive consequences of attachment-related strategies. Motivation and Emotion, 27(2), 77-102.

Mineka, S., \& Hendersen, R. W. (1985). Controllability and predictability in acquired motivation. Annual Review of Psychology, 36(1), 495-529. https://doi.org/10.1146/annurev.ps.36.020185.002431

Mogg, K., \& Bradley, B. P. (2016). Anxiety and attention to threat: Cognitive mechanisms and 
treatment with attention bias modification. Behaviour Research and Therapy, 87, 76-108. https://doi.org/10.1016/j.brat.2016.08.001

Molendijk, M. L., Bus, B. A. A., Spinhoven, P., Kaimatzoglou, A., Voshaar, R. C. O., Penninx, B. W. J. H., ... Elzinga, B. M. (2012). A systematic review and meta-analysis on the association between BDNF val66met and hippocampal volume-A genuine effect or a winners curse? American Journal of Medical Genetics Part B: Neuropsychiatric Genetics, 159(6), 731-740.

Nolte, T., Uiney, J., Fonagy, P., Mayes, L. C., \& Luyten, P. (2011). Interpersonal stress regulation and the development of anxiety disorders: An attachment-based developmental framework. Frontiers in Behavioral Neuroscience, 5, 1-21. https://doi.org/10.3389/fnbeh.2011.00055

Orcutt, H. K., Garcia, M., \& Pickett, S. M. (2016). Female-perpetrated intimate partner violence and romantic attachment style in a college student sample. In R. D. Maiuro (Ed.), Perspectives on college sexual assault: Perpetrator, victim, and bystander. (pp. 151-166). New York, NY: Springer Publishing Co.

Otowa, T., Hek, K., Lee, M., Byrne, E. M., Mirza, S. S., Nivard, M. G., ... Wolen, A. (2016). Meta-analysis of genome-wide association studies of anxiety disorders. Molecular Psychiatry, 21(10), 1391.

*Pace, C. S., Di Folco, S., Guerriero, V., Santona, A., \& Terrone, G. (2015). Adoptive parenting and attachment: Association of the internal working models between adoptive mothers and their late-adopted children during adolescence. Frontiers in Psychology, 6(1433), 1-11. https://doi.org/10.3389/fpsyg.2015.01433

Pacheco-Unguetti, A. P., Acosta, A., Callejas, A., \& Lupiáñez, J. (2010). Attention and anxiety: 
Different attentional functioning under state and trait anxiety. Psychological Science, 21(2), 298-304. https://doi.org/10.1177/0956797609359624

Patriquin, M. A., \& Mathew, S. J. (2017). The neurobiological mechanisms of generalized anxiety disorder and chronic stress. Chronic Stress, 1, 1-10. https://doi.org/10.1177/2470547017703993

*Pianta, R. C., Egeland, B., \& Adam, E. K. (1996). Adult attachment classification and selfreported psychiatric symptomatology as assessed by the Minnesota Multiphasic Personality Inventory--2. Journal of Consulting and Clinical Psychology, 64(2), 273-281. https://doi.org/10.1037/0022-006X.64.2.273

*Piermattei, C., Pace, C. S., Tambelli, R., D’Onofrio, E., \& Di Folco, S. (2017). Late adoptions: Attachment security and emotional availability in mother-child and father-child dyads. Journal of Child and Family Studies, 26(8), 2114-2125. https://doi.org/10.1007/s10826017-0732-6

R Core Team. (2019). R: A language and environment for statistical computing. R Foundation for Statistical Computing, Vienna, Austria. Retrieved from https://www.r-project.org/.

*Raby, K. L., Yarger, H. A., Lind, T., Fraley, R. C., \& Leerkes, E. (2017). Attachment states of mind among internationally adoptive and foster parents. Development and Psychopathology, 29, 365-378. https://doi.org/10.1017/S0954579417000049

Remes, O., Brayne, C., Van Der Linde, R., \& Lafortune, L. (2016). A systematic review of reviews on the prevalence of anxiety disorders in adult populations. Brain and Behavior, 6(7), e00497.

Roisman, G. I. (2006). The role of adult attachment security in non-romantic, non-attachmentrelated first interactions between same-sex strangers. Attachment and Human Development, 
8(4), 341-352. https://doi.org/10.1080/14616730601048217

Roisman, G. I. (2007). The psychophysiology of adult attachment relationships: Autonomic reactivity in marital and premarital interactions. Developmental Psychology, 43(1), 39-53. https://doi.org/10.1037/0012-1649.43.1.39

Roisman, G. I., \& Cicchetti, D. (2017). Attachment in the context of atypical caregiving. Development and Psychopathology, 29(2), 331-335. https://doi.org/DOI: $10.1017 / \mathrm{S} 0954579417000013$

*Roisman, G. I., Clausell, E., Holland, A., Fortuna, K., \& Elieff, C. (2008). Adult romantic relationships as contexts of human development: A multimethod comparison of same-sex couples with opposite-sex dating, engaged, and married dyads. Developmental Psychology, 44(1), 91-101. https://doi.org/10.1037/0012-1649.44.1.91

Roisman, G. I., Fortuna, K., \& Holland, A. (2006). An Experimental Manipulation of Retrospectively Defined Earned and Continuous Attachment Security. Child Development, 77(1), 59-71. https://doi.org/10.1111/j.1467-8624.2006.00856.x

Roisman, G. I., Holland, A., Fortuna, K., Fraley, R. C., Clausell, E., \& Clarke, A. (2007). The Adult Attachment Interview and self-reports of attachment style: An empirical rapprochement. Journal of Personality and Social Psychology, 92(4), 678-697. https://doi.org/10.1037/0022-3514.92.4.678

*Roisman, G. I., Padrón, E., Sroufe, L. A., \& Egeland, B. (2002). Earned-secure attachment status in retrospect and prospect. Child Development, 73(4), 1204-1219. https://doi.org/10.1111/1467-8624.00467

Roisman, G. I., Rogosch, F. A., Cicchetti, D., Groh, A. M., Haltigan, J. D., Haydon, K. C., ... Steele, R. D. (2017). Attachment states of mind and inferred childhood experiences in 
maltreated and comparison adolescents from low-income families. Development and Psychopathology, 29(2), 337-345. https://doi.org/10.1017/S0954579417000025

*Roisman, G. I., Tsai, J. L., \& Chiang, K.-H. S. (2004). The emotional integration of childhood experience: Physiological, facial expressive, and self-reported emotional response during the Adult Attachment Interview. Developmental Psychology, 40(5), 776-789. https://doi.org/10.1037/0012-1649.40.5.776

Rosenstein, D. S., \& Horowitz, H. A. (1996). Adolescent attachment and psychopathology. Journal of Consulting and Clinical Psychology, 64(2), 244-253. https://doi.org/10.1037/0022-006X.64.2.244

*Scharf, M., Mayseless, O., \& Kivenson-Baron, I. (2011). Leaving the parental nest: Adjustment problems, attachment representations, and social support during the transition from high school to military service. Journal of Clinical Child and Adolescent Psychology, 40(3), 411-423. https://doi.org/10.1080/15374416.2011.563464

*Scharf, M., Mayseless, O., \& Kivenson-Baron, I. (2012). Intergenerational concordance in adult attachment interviews with mothers, fathers and adolescent sons and subsequent adjustment of sons to military service. Attachment \& Human Development, 14(4), 367-390. https://doi.org/10.1080/14616734.2012.691652

*Scheidt, C. E., Hasenburg, A., Kunze, M., Waller, E., Pfeifer, R., Zimmermann, P., ... Waller, N. (2012). Are individual differences of attachment predicting bereavement outcome after perinatal loss? A prospective cohort study. Journal of Psychosomatic Research, 73(5), 375382. https://doi.org/10.1016/j.jpsychores.2012.08.017

Schooler, J. (2011). Unpublished results hide the decline effect: Some effects diminish when tests are repeated. Nature, 470(7335), 437-438. 
Scott, K. M., Smith, D. R., \& Ellis, P. M. (2010). Prospectively ascertained child maltreatment and its association with DSM-IV mental disorders in young adults maltreatment and mental disorders in young adults. JAMA Psychiatry, 67(7), 712-719. https://doi.org/10.1001/archgenpsychiatry.2010.71

Seiffge-Krenke, I., \& Beyers, W. (2005). Coping trajectories from adolescence to young adulthood: Links to attachment state of mind. Journal of Research on Adolescence, 15(4), $561-582$.

Shalev, A., Liberzon, I., \& Marmar, C. (2017). Post-traumatic stress disorder. New England Journal of Medicine, 376(25), 2459-2469.

Shaver, P. R., \& Mikulincer, M. (2007). Adult attachment strategies and the regulation of emotion. In J. J. Gross (Ed.), Handbook of emotion regulation (pp. 446-465). New York, NY: Guilford Press.

Simpson, H. B., Neria, Y., Lewis-Fernandez, R., \& Schneier, F. (Eds.). (2010). Anxiety disorders, theory, research, and clinical perspectives. Cambridge University Press, Cambridge.

Slade, A. (1999). Attachment theory and research: Implications for the theory and practice of individual psychotherapy with adults. Handbook of Attachment: Theory, Research, and Clinical Applications. New York, NY, US: The Guilford Press.

Sroufe, L. A. (1996). Cambridge studies in social \& emotional development. Emotional development: The organization of emotional life in the early years. Cambridge University Press.

Sroufe, L. A., Duggal, S., Weinfield, N., \& Carlson, E. (2000). Relationships, development, and psychopathology. In A. J. Sameroff, M. Lewis, \& S. M. Miller (Eds.), Handbook of 
developmental psychopathology (pp. 75-91). Springer, Boston, MA. https://doi.org/http://dx.doi.org/10.1007/978-1-4615-4163-9_5

Sroufe, L. A., Egeland, B., Carlson, E., \& Collins, W. A. (2005). The development of the person: The Minnesota study of risk and adaptation from birth to adulthood. New York: Guilford.

Sroufe, L. A., \& Waters, E. (1977). Attachment as an organizational construct. Child Development, 48(4), 1184. https://doi.org/10.2307/1128475

Steel, Z., Marnane, C., Iranpour, C., Chey, T., Jackson, J. W., Patel, V., \& Silove, D. (2014). The global prevalence of common mental disorders: A systematic review and meta-analysis 1980-2013. International Journal of Epidemiology, 43(2), 476-493. https://doi.org/10.1093/ije/dyu038

Steele, R. D., Waters, T. E. A., Bost, K. K., Vaughn, B. E., Truitt, W., Waters, H. S., ... Roisman, G. I. (2014). Caregiving antecedents of secure base script knowledge: A comparative analysis of young adult attachment representations. Developmental Psychology, 50(11), 2526-2538. https://doi.org/10.1037/a0037992

Stovall-McClough, K C, \& Dozier, M. (2016). Attachment states of mind and psychopathology in adulthood. In J Cassidy \& P. R. Shaver (Eds.), Handbook of attachment: Theory, research and clinical applications (3rd ed., pp. 715-738). New York, NY: Guilford Press.

Stovall-McClough, K. C., \& Cloitre, M. (2006). Unresolved attachment, PTSD, and dissociation in women with childhood abuse histories. Journal of Consulting and Clinical Psychology, 74(2), 219-228. https://doi.org/10.1037/0022-006X.74.2.219

Stuart Parrigon, K. L., \& Kerns, K. A. (2016). Family processes in child anxiety: The long-term impact of fathers and mothers. Journal of Abnormal Child Psychology, 44(7), 1253-1266. https://doi.org/10.1007/s10802-015-0118-4 
*Tarabulsy, G. M., Larose, S., Bernier, A., Trottier-Sylvain, K., Girard, D., Vargas, M., \& Noël, C. (2012). Attachment states of mind in late adolescence and the quality and course of romantic relationships in adulthood. Attachment \& Human Development, 14(6), 621-643. https://doi.org/10.1080/14616734.2012.728358

Thompson, R. A. (2001). Childhood anxiety disorders from the perspective of emotion regulation. In M. W. Vasey \& M. R. Dadds (Eds.), The developmental psychopathology of anxiety (pp. 160-182). New York: Oxford University.

*Van Emmichoven, I. A. Z., Van IJzendoorn, M. H., De Ruiter, C., \& Brosschot, J. F. (2003). Selective processing of threatening information: Effects of attachment representation and anxiety disorder on attention and memory. Development and Psychopathology, 15(1), 219237. https://doi.org/10.1017/S0954579403000129

Verhage, M. L., Schuengel, C., Madigan, S., Fearon, R. M. P., Oosterman, M., Cassibba, R., ... Van Ijzendoorn, M. H. (2016). Narrowing the transmission gap: A synthesis of three decades of research on intergenerational transmission of attachment. Psychological Bulletin, 142(4), 337-366. https://doi.org/10.1037/bu10000038

Viechtbauer, W. (2005). Bias and efficiency of meta-analytic variance estimators in the randomeffects model. Journal of Educational and Behavioral Statistics, 30(3), 261-293. https://doi.org/https://doi.org/10.3102\%2F10769986030003261

Viechtbauer, W. (2010). Conducting meta-analyses in R with the metafor package. Journal of Statistical Software, 36(3), 1-48. https://doi.org/http://www.jstatsoft.org/v36/i03/ Viechtbauer, W., \& Cheung, M. W.-L. (2010). Outlier and influence diagnostics for metaanalysis. Research Synthesis Methods, 1, 112-125. https://doi.org/10.1002/jrsm.11

Walker, E. R., McGee, R. E., \& Druss, B. G. (2015). Mortality in mental disorders and global 
disease burden implications: A systematic review and meta-analysis. JAMA Psychiatry, 72(4), 334-341.

Warren, S. L., Huston, L., Egeland, B., \& Sroufe, L. A. (1997). Child and adolescent anxiety disorders and early attachment. Journal of the American Academy of Child \& Adolescent Psychiatry, 36(5), 637-644. https://doi.org/10.1097/00004583-199705000-00014

Waters, T. E., \& Roisman, G. I. (2019). The secure base script concept: An overview. Current Opinion in Psychology, 25, 162-166. https://doi.org/10.1016/j.copsyc.2018.08.002

Whiteford, H. A., Degenhardt, L., Rehm, J., Baxter, A. J., Ferrari, A. J., Erskine, H. E., ... Vos, T. (2013). Global burden of disease attributable to mental and substance use disorders: findings from the Global Burden of Disease Study 2010. The Lancet, 382(9904), 15751586. https://doi.org/10.1016/S0140-6736(13)61611-6

Widiger, T. A., \& Samuel, D. B. (2005). Diagnostic categories or dimensions? A question for the Diagnostic and statistical manual of mental disorders--fifth edition. Journal of Abnormal Psychology, 114(4), 494-504. https://doi.org/10.1037/0021-843X.114.4.494

Wright, A. G. C., Krueger, R. F., Hobbs, M. J., Markon, K. E., Eaton, N. R., \& Slade, T. (2013). The structure of psychopathology: Toward an expanded quantitative empirical model. Journal of Abnormal Psychology, 122(1), 281-294. https://doi.org/10.1037/a0030133

Yiend, J., \& Mathews, A. (2001). Anxiety and attention to threatening pictures. The Quarterly Journal of Experimental Psychology Section A, 54(3), 665-681. https://doi.org/10.1080/713755991

Zvolensky, M. J., Garey, L., \& Bakhshaie, J. (2017). Disparities in anxiety and its disorders. Journal of Anxiety Disorders, 48, 1-5. https://doi.org/https://doi.org/10.1016/j.janxdis.2017.05.004 
Table 1. Description of samples.

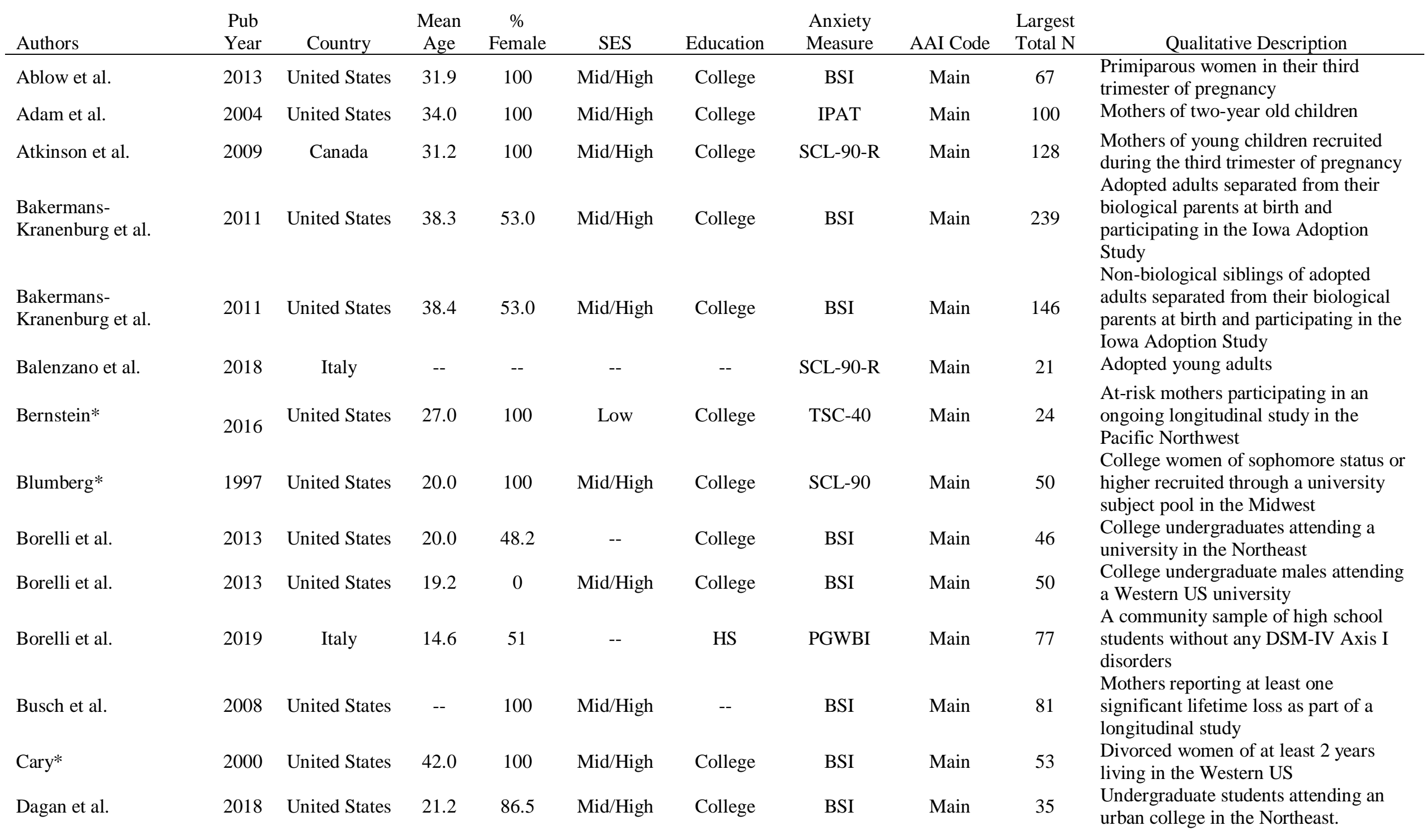




\begin{tabular}{|c|c|c|c|c|c|c|c|c|c|c|}
\hline Dagan et al. & 2018 & United States & 20.1 & 72.0 & Mid/High & College & BSI & Main & 49 & $\begin{array}{l}\text { Undergraduate students attending a } \\
\text { suburban university in the Northeast. }\end{array}$ \\
\hline Dawson et al. & 2014 & United States & 14.3 & 52.0 & Mid/High & HS & BAI & Q-Sort & 161 & $\begin{array}{l}\text { Socioeconomically and ethnically } \\
\text { diverse adolescents participating in a } \\
\text { longitudinal study of social } \\
\text { development }\end{array}$ \\
\hline Ehrlich et al. & 2011 & United States & 16.5 & 62.4 & Mid/High & HS & CBCL & Main & 180 & $\begin{array}{l}\text { Adolescents recruited from local high } \\
\text { schools in a large metropolitan area }\end{array}$ \\
\hline Finger* & 2006 & United States & 26.82 & 100 & Mid/High & College & MCMI-III & Main & 63 & $\begin{array}{l}\text { Mothers of young children recruited } \\
\text { from community clinics }\end{array}$ \\
\hline Fortuna et al. & 2011 & United States & 21.7 & 50.0 & Mid/High & College & ASR & Q-Sort & 60 & $\begin{array}{l}\text { Oldest sibling from a sample of } \\
\text { biologically related siblings recruited } \\
\text { from the Midwest }\end{array}$ \\
\hline Fortuna et al. & 2011 & United States & 19.2 & 50.0 & Mid/High & College & ASR & Q-Sort & 60 & $\begin{array}{l}\text { Youngest sibling from a sample of } \\
\text { biologically related siblings recruited } \\
\text { from the Midwest }\end{array}$ \\
\hline Gralinski-Bakker et al. & 2004 & United States & 25.8 & 50.0 & Mid/High & College & SCL-90-R & Main & 65 & $\begin{array}{l}\text { Living members of a longitudinal } \\
\text { sample who had been initially recruited } \\
\text { as high school students in } 1978\end{array}$ \\
\hline Haydon et al. & 2014 & United States & 17.8 & 51.7 & Mid/High & HS & YSR & Main & 807 & $\begin{array}{l}\text { Participants recruited as part of the } \\
\text { Study of Early Child Care and Youth } \\
\text { Development (SECCYD) }\end{array}$ \\
\hline Holland and Roisman & 2010 & United States & 20.71 & 0 & Mid/High & College & ASR & Q-Sort & 114 & $\begin{array}{l}\text { Exclusively dating males recruited from } \\
\text { a small Midwest town }\end{array}$ \\
\hline Holland and Roisman & 2010 & United States & 20.14 & 100 & Mid/High & College & ASR & Q-Sort & 114 & $\begin{array}{l}\text { Exclusively dating females recruited } \\
\text { from a small Midwest town }\end{array}$ \\
\hline Hughes et al. & 2004 & $\begin{array}{l}\text { United } \\
\text { Kingdom }\end{array}$ & -- & 100 & -- & -- & STAI & Main & 60 & $\begin{array}{l}\text { Primigravid mothers serving as controls } \\
\text { and assessed during the third trimester } \\
\text { of pregnancy }\end{array}$ \\
\hline Jones-Mason et al. & 2016 & United States & 19.8 & 81.2 & Mid/High & College & BAI & Main & 119 & $\begin{array}{l}\text { College students attending a public } \\
\text { university in the Western US }\end{array}$ \\
\hline Kobak \& Sceery & 1988 & United States & 18.2 & 50.9 & Mid/High & College & HSCL-90 & Q-Sort & 53 & $\begin{array}{l}\text { Primarily middle-class first-year } \\
\text { college students }\end{array}$ \\
\hline Kobak et al. & 2009 & United States & 15.0 & 51.0 & Low & HS & YSR & Q-Sort & 198 & $\begin{array}{l}\text { Economically disadvantaged } \\
\text { adolescents }\end{array}$ \\
\hline $\begin{array}{l}\text { Koren-Karie and } \\
\text { Getzler-Yosef }\end{array}$ & 2018 & Israel & 42.9 & 100 & Mid/High & College & BSI & Main & 30 & $\begin{array}{l}\text { Comparison group mothers with no } \\
\text { reported history of child abuse }\end{array}$ \\
\hline
\end{tabular}




\begin{tabular}{|c|c|c|c|c|c|c|c|c|c|c|}
\hline Pace et al. & 2015 & Italy & 51.5 & 100 & Mid/High & College & SCL-90-R & Main & 30 & $\begin{array}{l}\text { Adoptive mothers of late-adolescents } \\
\text { from international adoption agencies }\end{array}$ \\
\hline Pianta et al. & 1996 & United States & 22.0 & 100 & Low & HS & MMPI-2 & Main & 110 & $\begin{array}{l}\text { High-risk first-time mothers recruited } \\
\text { during their second trimester of } \\
\text { pregnancy to serve as controls for a } \\
\text { preventive intervention program }\end{array}$ \\
\hline Piermattei et al. & 2017 & Italy & 46.0 & 0 & Mid/High & HS & SCL-90-R & Main & 20 & $\begin{array}{l}\text { Adoptive fathers of late-adopted } \\
\text { children }\end{array}$ \\
\hline Piermattei et al. & 2017 & Italy & 44.8 & 100 & Mid/High & College & SCL-90-R & Main & 18 & $\begin{array}{l}\text { Adoptive mothers of late-adopted } \\
\text { children }\end{array}$ \\
\hline Raby et al. & 2017 & United States & 39.6 & 95.5 & Mid/High & College & BSI & Main & 130 & Internationally adoptive parents \\
\hline Raby et al. & 2017 & United States & 26.3 & 98.5 & Low & HS & PDSQ & Main & 189 & $\begin{array}{l}\text { Parents of young children living in } \\
\text { poverty and involved with Child } \\
\text { Protective Services }\end{array}$ \\
\hline Raby et al. & 2017 & United States & 42.4 & 94.2 & Mid/High & College & BSI & Main & 149 & Foster parents of toddlers \\
\hline Roisman et al. & 2002 & United States & 26.0 & 49.7 & Low & College & YASR & Main & 163 & $\begin{array}{l}\text { A subsample of the children of mothers } \\
\text { who had participated in the Minnesota } \\
\text { Longitudinal Study of Risk and } \\
\text { Adaptation }\end{array}$ \\
\hline Roisman et al. & 2004 & United States & 21.5 & 53.3 & Mid/High & College & YASR & Q-Sort & 60 & $\begin{array}{l}\text { Young undergraduate and graduate } \\
\text { students from a Midwestern university }\end{array}$ \\
\hline Roisman et al. & 2008 & United States & 33.97 & 0 & Mid/High & College & ASR & Q-Sort & 30 & $\begin{array}{l}\text { Gay men within a committed } \\
\text { relationship for at least a year (group 1) }\end{array}$ \\
\hline Roisman et al. & 2008 & United States & 32.77 & 0 & Mid/High & College & ASR & Q-Sort & 30 & $\begin{array}{l}\text { Gay men within a committed } \\
\text { relationship for at least a year (group 2) }\end{array}$ \\
\hline Roisman et al. & 2008 & United States & 35.07 & 100 & Mid/High & College & ASR & Q-Sort & 30 & $\begin{array}{l}\text { Gay women within a committed } \\
\text { relationship for at least a year (group 1) }\end{array}$ \\
\hline Roisman et al. & 2008 & United States & 34.4 & 100 & Mid/High & College & ASR & Q-Sort & 30 & $\begin{array}{l}\text { Gay women within a committed } \\
\text { relationship for at least a year (group } 2 \text { ) }\end{array}$ \\
\hline Roisman et al. & 2008 & United States & 22.72 & 0 & Mid/High & College & ASR/YASR & Q-Sort & 50 & Young, first time engaged men \\
\hline Roisman et al. & 2008 & United States & 22.24 & 100 & Mid/High & College & ASR/YASR & Q-Sort & 50 & Young, first time engaged women \\
\hline Roisman et al. & 2008 & United States & 57.98 & 0 & Mid/High & College & ASR/YASR & Q-Sort & 40 & $\begin{array}{l}\text { Men who were married for at least } 15 \\
\text { years }\end{array}$ \\
\hline Roisman et al. & 2008 & United States & 55.78 & 100 & Mid/High & College & ASR/YASR & Q-Sort & 40 & $\begin{array}{l}\text { Women who were married for at least } \\
15 \text { years }\end{array}$ \\
\hline
\end{tabular}




\begin{tabular}{|c|c|c|c|c|c|c|c|c|c|c|}
\hline Scharf et al. & 2011 & Israel & 17.5 & 100 & Mid/High & HS & MHI & Main & 110 & $\begin{array}{l}\text { Late-adolescent female seniors in high } \\
\text { school soon to begin compulsory } \\
\text { military service }\end{array}$ \\
\hline Scharf et al. & 2012 & Israel & 17.5 & 0 & Mid/High & HS & MHI & Main & 85 & $\begin{array}{l}\text { Late-adolescent male students with } \\
\text { senior high school status participating } \\
\text { in a longitudinal study }\end{array}$ \\
\hline Scheidt et al. & 2012 & Germany & 35.2 & 100 & -- & College & HADS & Q-Sort & 31 & $\begin{array}{l}\text { Women recruited from a university } \\
\text { hospital in Germany who had lost a } \\
\text { child due to miscarriage or perinatal } \\
\text { death }\end{array}$ \\
\hline Tarabulsy et al. & 2012 & Canada & 28.4 & 65 & Mid/High & College & SCL-90-R & Main & 99 & $\begin{array}{l}\text { At-risk college students receiving } \\
\text { academic advising services whoe were } \\
\text { followed up a decade later }\end{array}$ \\
\hline van Emmichoven et al. & 2003 & Netherlands & 36.7 & 67.9 & -- & -- & ADIS-R & Main & 84 & $\begin{array}{l}\text { Primarily female healthy controls } \\
\text { recruited from the general population }\end{array}$ \\
\hline
\end{tabular}

Note. ADIS-R = Anxiety Disorders Interview Schedule-Revised; ASR = Adult Self-Report (anxiety subscale); BAI = Beck Anxiety Inventory II; BSI= Brief Symptom Inventory (anxiety subscale); CBCL = Child Behavior Checklist/6-18 (anxiety subscale); HADS = Hospital Anxiety and Depression Scale (anxiety subscale); HSCL-90 = The Hopkins Symptom Checklist-90; IPAT = Personality and Ability Testing (anxiety subscale); MCMI-III = The Millon Clinical Multiaxial Inventory III; MHI = Mental Health Inventory (anxiety subscale); PDSQ = Psychiatric Diagnostic Screening Questionnaire (anxiety subscale); PGWBI = The Psychological general WellBeing Index (anxiety subscale); SCL-90/-R = Symptom Checklist-90/-Revised (anxiety subscale); TSC-40 = The Trauma Symptom Checklist-40 (anxiety subscale); YASR = Young Adult Self Report/18-30 (anxiety subscale); YSR = Youth Self-Report/11-18 (anxiety subscale); Q-sort = AAI Q-sort (Kobak et al., 1993); Main = AAI classification system $($ Main \& Goldwyn, 1998); * = Dissertation 
Table 2. Moderators.

\begin{tabular}{|c|c|c|c|c|c|c|c|c|c|}
\hline & & & Secure & Insecure & & & Secure $v$ & ismissing & \\
\hline Moderators & & $k$ & $\beta$ & $Q(d f)$ & $p$ & $k$ & $\beta$ & $Q(d f)$ & $p$ \\
\hline Publication Type & & & & $0.36(1)$ & .55 & & & -- & - \\
\hline Peer-review & $\beta_{0}$ & 46 & 0.06 & & & & & & \\
\hline Dissertation & $\beta_{1}$ & 4 & 0.11 & & & & & & \\
\hline Country & & & & $0.00(1)$ & 1.0 & & & $0.44(1)$ & .51 \\
\hline Other & $\beta_{0}$ & 13 & 0.07 & & & 12 & 0.03 & & \\
\hline United States & $\beta_{1}$ & 37 & -0.0002 & & & 38 & -0.07 & & \\
\hline SES & & & & $0.72(1)$ & .40 & & & $5.89(1)$ & .02 \\
\hline Low & $\beta_{0}$ & 4 & -0.03 & & & 5 & -0.23 & & \\
\hline Mid/High & $\beta_{1}$ & 39 & 0.09 & & & 39 & 0.23 & & \\
\hline Education & & & & $1.47(1)$ & .23 & & & $0.10(1)$ & .75 \\
\hline Some College or More & $\beta_{0}$ & 38 & 0.09 & & & 37 & -0.05 & & \\
\hline High School or Less & $\beta_{1}$ & 9 & -0.10 & & & 10 & 0.03 & & \\
\hline Race & & & & $3.38(1)$ & .07 & & & 4.24 & .04 \\
\hline$<60 \%$ White & $\beta_{0}$ & 9 & -0.05 & & & 10 & -0.14 & & \\
\hline$>60 \%$ White & $\beta_{1}$ & 36 & 0.15 & & & 37 & 0.16 & & \\
\hline Risk Status & & & & $0.15(1)$ & .70 & & & $1.39(1)$ & .24 \\
\hline Non-risk & $\beta_{0}$ & 43 & 0.07 & & & 43 & -0.002 & & \\
\hline Risk & $\beta_{1}$ & 7 & -0.04 & & & 7 & -0.12 & & \\
\hline Parent vs. Non-parent & & & & $0.14(1)$ & .71 & & & 1.62 & .20 \\
\hline Majority non-parents & $\beta_{0}$ & 13 & 0.05 & & & 13 & -0.02 & & \\
\hline Majority parents & $\beta_{1}$ & 15 & -0.04 & & & 15 & -0.15 & & \\
\hline Adolescent vs. Adult & & & & $0.14(1)$ & .71 & & & $1.05(1)$ & .31 \\
\hline$<18$ & $\beta_{0}$ & 6 & 0.03 & & & 7 & 0.04 & & \\
\hline$\geq 18$ & $\beta_{1}$ & 44 & 0.04 & & & 43 & -0.09 & & \\
\hline Concurrent Assessment & & & & $0.28(1)$ & .60 & & & $1.14(1)$ & .29 \\
\hline Concurrent & $\beta_{0}$ & 17 & 0.03 & & & 17 & -0.14 & & \\
\hline Non-concurrent & $\beta_{1}$ & 7 & -0.05 & & & 7 & 0.12 & & \\
\hline AAI coding system & & & & $0.33(1)$ & .57 & & & $1.26(1)$ & .26 \\
\hline Main & $\beta_{0}$ & 34 & 0.05 & & & 43 & -0.06 & & \\
\hline Q-sort & $\beta_{1}$ & 16 & 0.05 & & & 7 & 0.10 & & \\
\hline Publication Year & $\beta_{1}$ & 50 & -0.02 & $7.71(1)$ & .01 & 50 & -0.01 & $2.88(1)$ & .09 \\
\hline
\end{tabular}




\begin{tabular}{|c|c|c|c|c|c|c|c|c|c|}
\hline Mean Age & $\beta_{1}$ & 48 & 0.004 & $1.12(1)$ & .29 & 49 & -0.002 & $0.15(1)$ & .70 \\
\hline Percent Parent & $\beta_{1}$ & 28 & -0.0002 & $0.04(1)$ & .84 & 27 & -0.002 & $2.15(1)$ & .14 \\
\hline
\end{tabular}




\begin{tabular}{|c|c|c|c|c|c|c|c|c|c|c|c|c|c|}
\hline \multirow[b]{2}{*}{ Moderators } & & \multicolumn{4}{|c|}{ Secure vs. Preoccupied } & \multicolumn{4}{|c|}{ Preoccupied vs. Dismissing } & \multicolumn{4}{|c|}{ Resolved vs. Unresolved } \\
\hline & & $k$ & $\beta$ & $Q(d f)$ & $p$ & $k$ & $\beta$ & $Q(d f)$ & $p$ & $k$ & $\beta$ & $Q(d f)$ & $p$ \\
\hline Publication Type & & & & -- & -- & & & -- & -- & & & -- & -- \\
\hline Peer-review & $\beta_{0}$ & & & & & & & & & & & & \\
\hline Dissertation & $\beta_{1}$ & & & & & & & & & & & & \\
\hline Country & & & & $0.15(1)$ & .70 & & & $2.30(1)$ & .13 & & & $0.56(1)$ & .46 \\
\hline Other & $\beta_{0}$ & 8 & 0.27 & & & 7 & 0.03 & & & 6 & 0.41 & & \\
\hline United States & $\beta_{1}$ & 35 & 0.09 & & & 34 & 0.33 & & & 21 & -0.14 & & \\
\hline SES & & & & $0.60(1)$ & .44 & & & $5.07(1)$ & .02 & & & $0.65(1)$ & .42 \\
\hline Low & $\beta_{0}$ & 5 & 0.48 & & & 5 & 0.76 & & & 4 & 0.33 & & \\
\hline Mid/High & $\beta_{1}$ & 34 & -0.18 & & & 33 & -0.51 & & & 19 & -0.12 & & \\
\hline Education & & & & $0.14(1)$ & .70 & & & $0.09(1)$ & .76 & & & $0.33(1)$ & .56 \\
\hline Some College or More & $\beta_{0}$ & 31 & 0.37 & & & 31 & 0.34 & & & 20 & 0.31 & & \\
\hline High School or Less & $\beta_{1}$ & 9 & -0.07 & & & 8 & -0.06 & & & 4 & -0.08 & & \\
\hline Race & & & & $0.64(1)$ & .42 & & & $4.32(1)$ & .04 & & & $0.19(1)$ & .67 \\
\hline$<60 \%$ White & $\beta_{0}$ & 10 & 0.44 & & & 9 & 0.63 & & & 7 & 0.25 & & \\
\hline$>60 \%$ White & $\beta_{1}$ & 30 & -0.14 & & & 29 & -0.41 & & & 19 & 0.07 & & \\
\hline Risk Status & & & & $1.38(1)$ & .24 & & & $7.41(1)$ & .007 & & & $0.66(1)$ & .42 \\
\hline Non-risk & $\beta_{0}$ & 36 & 0.31 & & & 35 & .22 & & & 22 & 0.26 & & \\
\hline Risk & $\beta_{1}$ & 7 & 0.25 & & & 6 & .51 & & & 5 & 0.12 & & \\
\hline Parent vs. Non-parent & & & & $0.97(1)$ & .33 & & & $2.08(1)$ & .15 & & & $0.02(1)$ & .89 \\
\hline Majority non-parent & $\beta_{0}$ & 13 & 0.19 & & & 13 & 0.15 & & & 5 & 0.32 & & \\
\hline Majority parents & $\beta_{1}$ & 11 & 0.18 & & & 11 & 0.35 & & & 12 & 0.03 & & \\
\hline Adolescent vs. Adult & & & & $0.35(1)$ & .55 & & & $0.72(1)$ & .40 & & & -- & -- \\
\hline$<18$ & $\beta_{0}$ & 7 & 0.25 & & & 6 & 0.15 & & & & & & \\
\hline$\geq 18$ & $\beta_{1}$ & 36 & 0.12 & & & 35 & 0.19 & & & & & & \\
\hline Concurrent Assessment & & & & $2.07(1)$ & .15 & & & $4.81(1)$ & .03 & & & -- & -- \\
\hline Concurrent & $\beta_{0}$ & 15 & 0.44 & & & 14 & 0.62 & & & & & & \\
\hline Non-concurrent & $\beta_{1}$ & 7 & -0.32 & & & 7 & -0.58 & & & & & & \\
\hline AAI coding system & & & & $0.10(1)$ & .76 & & & $2.47(1)$ & .12 & & & -- & -- \\
\hline Main & $\beta_{0}$ & 27 & 0.37 & & & 26 & 0.41 & & & & & & \\
\hline Q-sort & $\beta_{1}$ & 16 & -0.05 & & & 15 & -0.25 & & & & & & \\
\hline Publication Year & $\beta_{1}$ & 43 & -0.02 & $2.72(1)$ & .10 & 41 & -0.01 & 0.31 & .58 & 27 & 0.01 & $1.53(1)$ & .22 \\
\hline
\end{tabular}




\begin{tabular}{lccccccccccccc} 
Mean Age & $\beta_{1}$ & 42 & 0.01 & $0.53(1)$ & .47 & 41 & 0.005 & $0.32(1)$ & .57 & 25 & 0.01 & $1.50(1)$ & .22 \\
Mean Education & $\beta_{1}$ & 13 & 0.03 & $0.26(1)$ & .61 & 12 & 0.09 & $1.40(1)$ & .24 & 9 & 0.04 & $0.67(1)$ & .41 \\
Percent Female & $\beta_{1}$ & 42 & 0.002 & $0.68(1)$ & .41 & 41 & 0.001 & $0.25(1)$ & .62 & 27 & 0.004 & $2.06(1)$ & .15 \\
Percent Parent & $\beta_{1}$ & 24 & 0.003 & $2.50(1)$ & .11 & 24 & 0.005 & $3.51(1)$ & .06 & 17 & 0.00 & $0.01(1)$ & .94 \\
Percent White & $\beta_{1}$ & 35 & -0.002 & $0.59(1)$ & .44 & 34 & -0.01 & $3.51(1)$ & .06 & 23 & -0.001 & $0.35(1)$ & .55 \\
\hline
\end{tabular}


Figure 1. Flow chart for study selection.

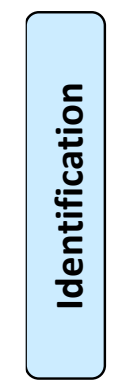

Records identified through PsycINFO, Medline, \& ProQuest $(\mathrm{n}=3,071)$

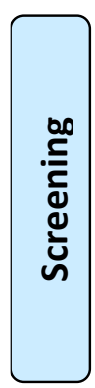

Records after duplicates removed

$$
(\mathrm{n}=3,088)
$$

Additional records identified through other sources

$(\mathrm{n}=17)$
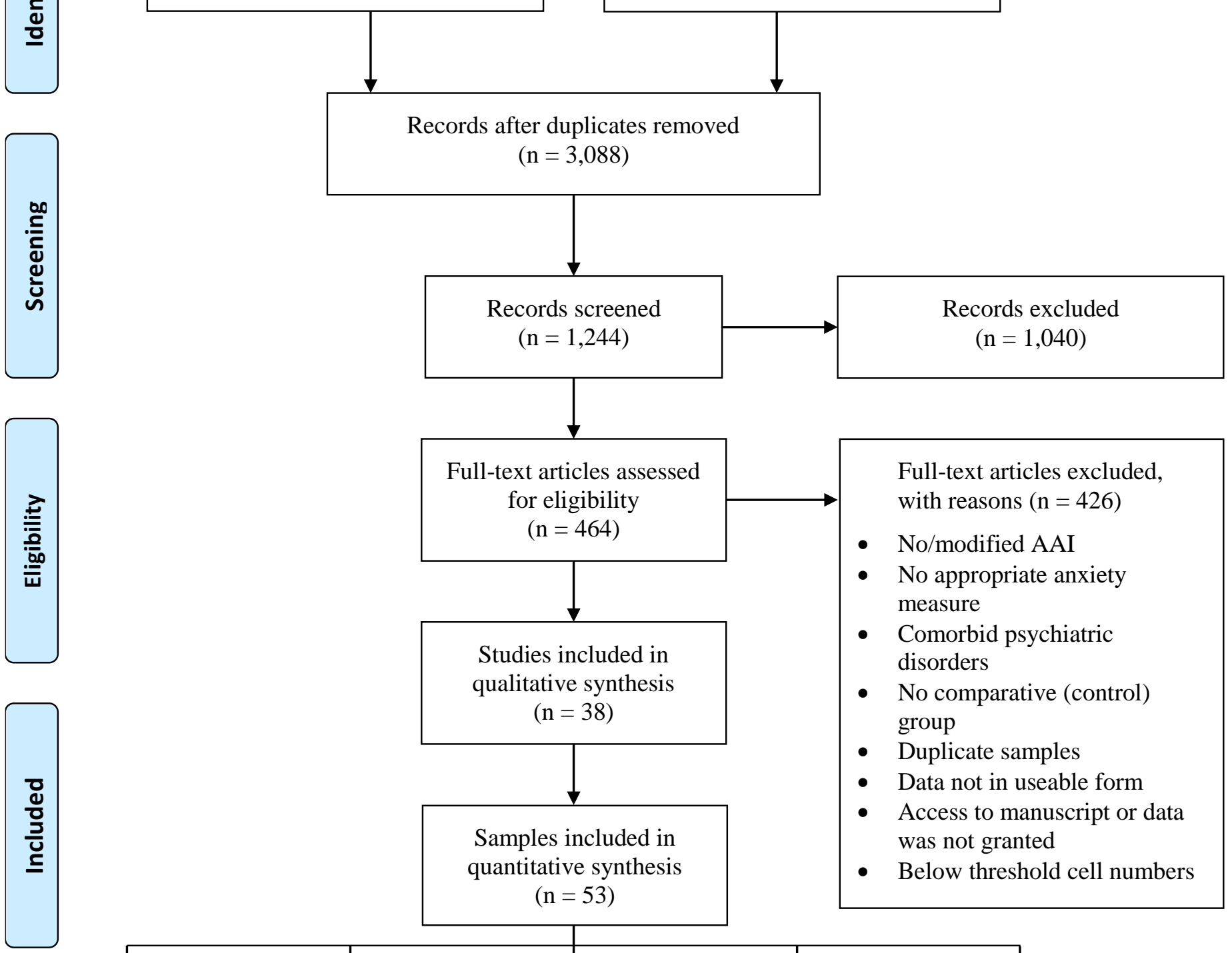

Studies included in qualitative synthesis

$$
(\mathrm{n}=38)
$$

Full-text articles assessed for eligibility

$$
(n=464)
$$

Full-text articles excluded, with reasons $(n=426)$

- No/modified AAI

- No appropriate anxiety measure

- Comorbid psychiatric disorders

- No comparative (control) group

- Duplicate samples

- Data not in useable form

- Access to manuscript or data was not granted

Samples included in quantitative synthesis $(\mathrm{n}=53)$

- Below threshold cell numbers

Secure vs Insecure $(\mathrm{n}=50)$

Secure vs.

Dismissing

$(\mathrm{n}=50)$
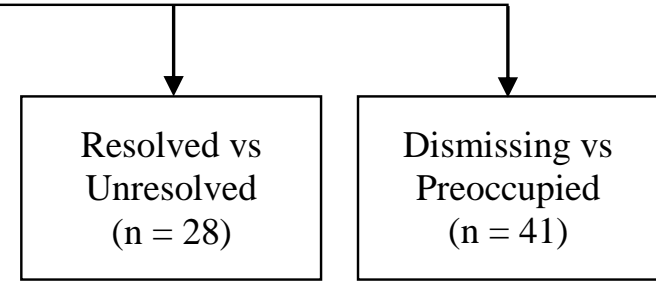
Figure 2. Effect size estimates for the secure versus Dismissing (a) and secure verses Preoccupied (b) comparisons computed as the standardized mean difference (Cohen's d).

\section{Secure versus Dismissing}

Author(s) and Year Ablow et al., 2013

Adkinson et al., 2009

Bakermans-Kranenburg et al., 2011 (AAS Sample) Bakermans-Kranenburg et al., 2011 (NBAS Sample) Balenzano et al., 201 Bernstein, 2016

Borelliet al, 2012 (WC Sample)

Borelli et al, 2012 (NEC Sample)

Borelli et al., 2019

Busch et al., 2008

Dagan et al., 2018 (NEUC Sample)

Dagan et al., 2018 (NESC Sample)

Dawson et al., 2014

Finger, 2006

Fortuna et al., 2011 (OS Sample)

Fortuna et al., 2011 (YS Sample)

Gralinski-Bakker et

Holland \& Roisman et al., 2010 (DM Sample)

Holland \& Roisman et al., 2010 (DF Sample)

Jones-Mason et al., 2016

Kobak \& Sceery, 1988

Koren-Karie \& Getzler-Yosef, 2018

Kuipers et al., 2016
Pianta et al. 1996

Piermattei et al., 2017 (M Samle)

Pample)

Raby et al., 2017 (FP Sample)

Raby et al, 2017 (IAPS Sample)

Roisman et al., 2006

Roisman et al., 2002

Roisman et al., 2008 (GM Sample

Roisman et al., 2008 (GM Sample 2)

Roisman et al., 2008 (LP Sample 1)

Roisman et al., 2008 (LP Sample 2)

Roisman et al., 2008 (EM Sample)

Roisman et al., 2008 (EF Sample)

Roisman et al., 2008 (MF Sample)

Scharf et al., 201

Scheidt et al., 2012

Tarabulsy et al., 2012

Zej,mans van Emmichoven et al., 2003

\section{RE Mode}

Sample Size

Cohen's d [ $95 \% \mathrm{Cl}]$
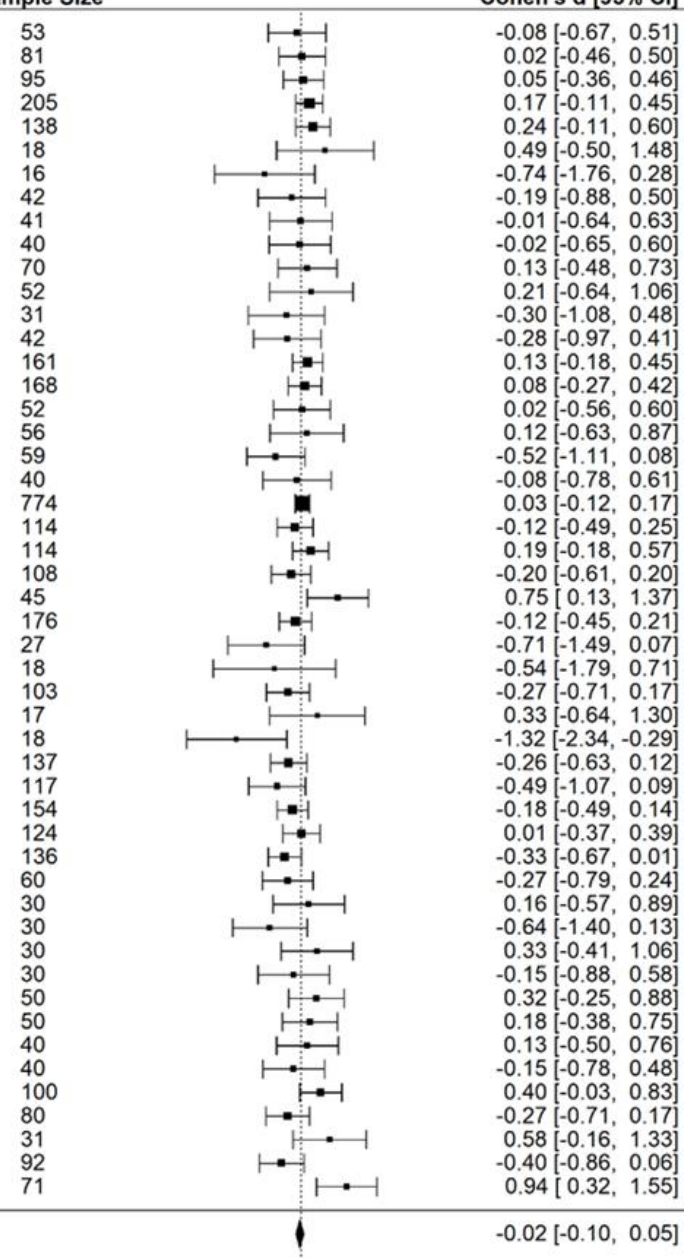

$\begin{array}{llllll}-3 & -2 & -1 & 0 & 1 & 2\end{array}$
Secure versus Preoccupied

\begin{tabular}{|c|c|c|c|}
\hline Author(s) and Year & Sample Size & & Cohen's d $[95 \% \mathrm{Cl}]$ \\
\hline Adam et al., 2004 & 76 & & $0.78[0.24,1.31]$ \\
\hline Atkinson et al., 2009 & 91 & & $0.47[0.04,0.90]$ \\
\hline Bakermans-Kranenburg et al., 2011 (AAS Sample) & 144 & & $0.87[0.43,1.31]$ \\
\hline Bakermans-Kranenburg et al. 2011 (NBAS Sample) & 95 & & $2.21[1.26,3.17]$ \\
\hline Bernstein, 2016 & 15 & 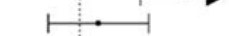 & $0.39[-0.65,1.43]$ \\
\hline Blumberg, 1997 & 39 & & $0.45[-0.33,1.23]$ \\
\hline Borelli et al., 2012 (WC Sample) & 32 & & $-0.09[-0.98,0.80]$ \\
\hline Borelli et al., 2019 & 64 & & $-0.19[-0.98,0.59]$ \\
\hline Busch et al., 2008 & 60 & 1. & $-0.40[-1.00,0.21]$ \\
\hline Dagan et al., 2018 (NEUC Sample) & 26 & & $0.86[-0.23,1.95]$ \\
\hline Dagan et al., 2018 (NESC Sample) & 38 & $\longmapsto$ & $-0.36[-1.18,0.47]$ \\
\hline Dawson et al., 2014 & 161 & & $0.70[0.37,1.03]$ \\
\hline Ehrlich et al.. 2011 & 134 & & $0.06[-0.59,0.70]$ \\
\hline Finger, 2006 & 28 & & $0.35[-0.41,1.12]$ \\
\hline Fortuna et al., 2011 (OS Sample) & 52 & & $0.92[-0.12,1.95]$ \\
\hline Gralinski-Bakker et al.. 2004 & 41 & & $0.07[-0.60,0.74]$ \\
\hline Haydon et al., 2014 & 522 & & $0.29[-0.06,0.64]$ \\
\hline Holland \& Roisman, 2010 (DM Sample) & 114 & & $-0.08[-0.45,0.29]$ \\
\hline Holland \& Roisman, 2010 (DF Sample) & 114 & & $0.16[-0.21,0.53]$ \\
\hline Jones-Mason et al., 2016 & 78 & & $-0.29[-1.20,0.61]$ \\
\hline Kobak \& Sceery, 1988 & 36 & $\longmapsto \vdash$ & $1.86[0.97,2.76]$ \\
\hline Kobak et al., 2009 & 71 & & $0.52[0.01,1.03]$ \\
\hline Pianta et al., 1996 & 83 & & $0.60[-0.18,1.37]$ \\
\hline Raby et al., 2017 (FP Sample) & 106 & $\mapsto$ & $1.48[0.74,2.23]$ \\
\hline Raby et al., 2017 (IAP Sample) & 113 & 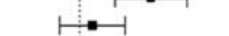 & $0.26[-0.42,0.95]$ \\
\hline Raby et al., 2017 (CPS Sample) & 92 & & $0.38[-0.10,0.86]$ \\
\hline Roisman et al., 2006 & 94 & & $0.52[-0.20,1.25]$ \\
\hline Roisman et al., 2002 & 101 & & $0.51[0.07,0.96]$ \\
\hline Roisman et al., 2004 & 60 & & $0.30[-0.22,0.82]$ \\
\hline Roisman et al., 2008 (GM Sample 1) & 30 & & $-0.16[-0.89,0.57]$ \\
\hline Roisman et al. 2008 (GM Sample 2) & 30 & & $0.08[-0.65,0.81]$ \\
\hline Roisman et al., 2008 (LP Sample 1) & 30 & 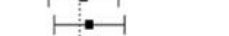 & $0.20[-0.53,0.93]$ \\
\hline Roisman et al., 2008 (LP Sample 2) & 30 & $\mapsto$ & $-0.23[-0.96,0.50]$ \\
\hline Roisman et al., 2008 (EM Sample) & 50 & & $0.12[-0.44,0.69]$ \\
\hline Roisman et al., 2008 (EF Sample) & 50 & & $0.42[-0.15,1.00]$ \\
\hline Roisman et al., 2008 (MM Sample) & 40 & $\mapsto-1$ & $-0.20[-0.83,0.43]$ \\
\hline Roisman et al., 2008 (MF Sample) & 40 & 1 & $0.12[-0.51,0.75]$ \\
\hline Scharf et al., 2011 & 79 & $\mapsto-1$ & $-0.40[-1.06,0.27]$ \\
\hline Scharf et al., 2012 & 47 & 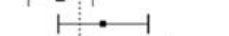 & $0.49[-0.44,1.42]$ \\
\hline Scheidt et al., 2012 & 31 & $\longmapsto-1$ & $1.09[0.28,1.91]$ \\
\hline Tarabulsy et al., 2012 & 73 & $\longmapsto$ & $-0.64[-1.43,0.14]$ \\
\hline Zeiilmans van Emmichoven, 2003 & 61 & $\longmapsto-1$ & $1.15[0.40,1.89]$ \\
\hline
\end{tabular}

RE Model

$\checkmark$

$0.35[0.19,0.50]$

Note. AAS $=$ Adopted adult siblings, NBAS $=$ Non-biologically related adult siblings, $\mathrm{WC}=$ Western college students, NEUC $=$ Northeastern urban college students, NESC = Northeastern suburban college students, OS = Oldest sibling, DM = Dating males, DF $=$ Dating females, FP $=$ Foster parents, $\mathrm{IAP}=$ Internationally Adoptive Parents, $\mathrm{CPS}=$ Child Protective Services, $\mathrm{GM}=$ Gay male partner, LP $=$ Lesbian partner, EM $=$ Engaged males, EF $=$ Engaged females, $\mathrm{MM}=$ Married males, $\mathrm{MF}=$ Married females 
Secure vs. Insecure

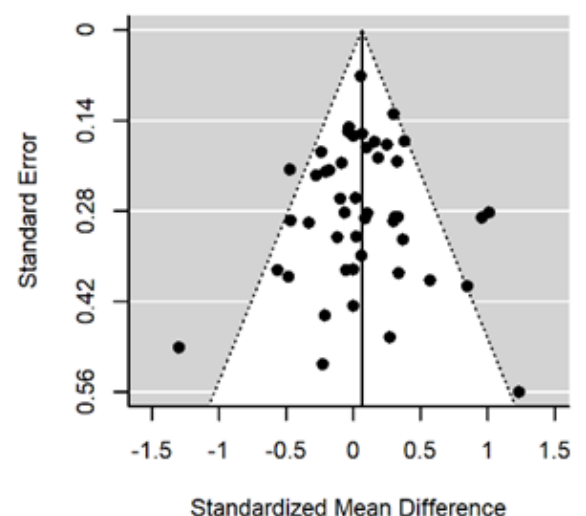

Secure vs. Preoccupied

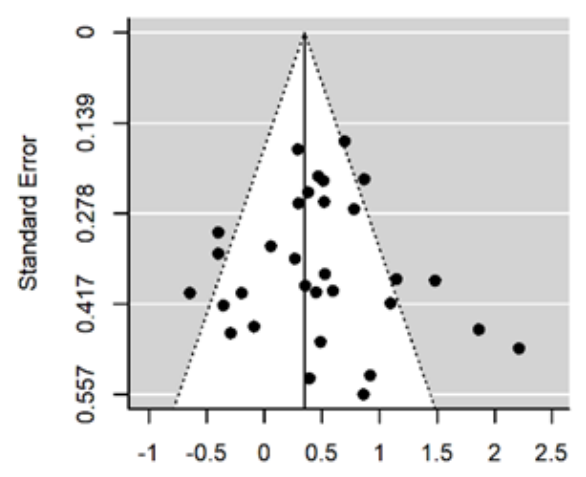

Standardized Mean Difference
Secure vs. Dismissing

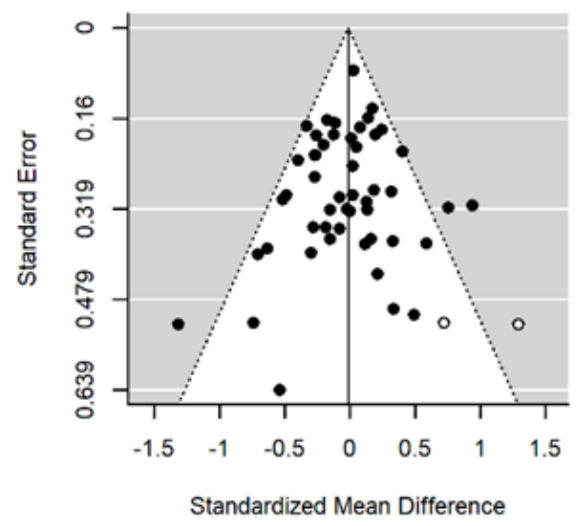

Preoccupied vs. Dismissing

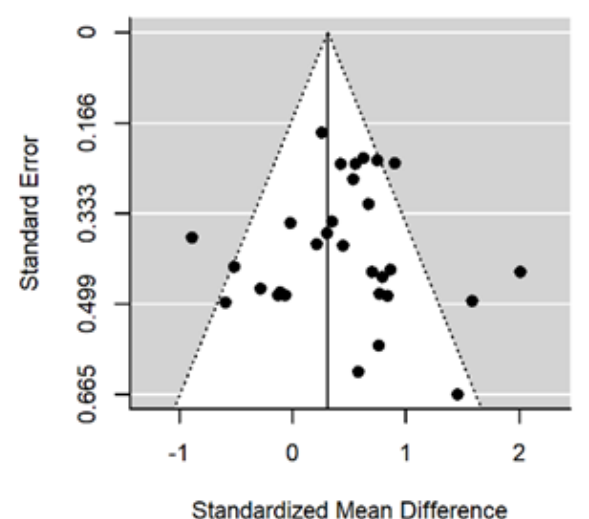

Resolved vs. Unresolved

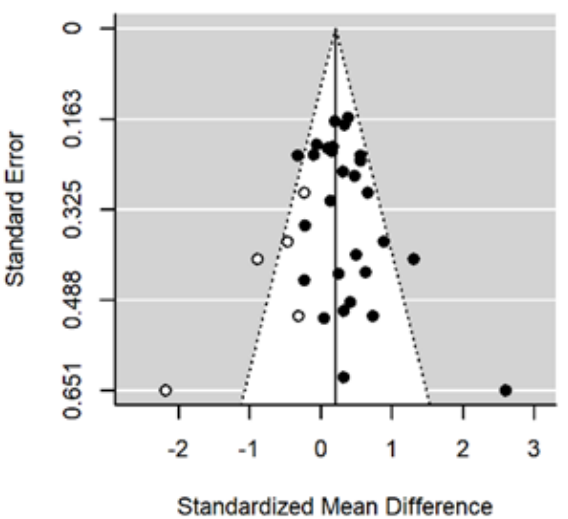

Figure 3. Funnel plots represent effect size point estimates by their standard error. Filled black circles represent observed effect size estimates included in the meta-analyses; Open white circles represent potentially missing studies imputed to correct for funnel plot asymmetry. Note: imputed studies in the bottom left corner of the graph may indicate publication bias (but see statistical output for adjusted mean effect). 